\title{
The Success of Stock Selection Strategies in EMERGING MARKETS: IS IT RISK OR BEHAVIORAL BIAS?
}

\section{Jaap van der Hart, Gerben de Zwart and Dick van Dijk}

\begin{tabular}{|l|l|}
\hline \multicolumn{2}{|l|}{ ERIM REPORT SERIES RESEARCH IN MANAGEMENT } \\
\hline ERIM Report Series reference number & ERS-2005-012-F\&A \\
\hline Publication & February 2005 \\
\hline Number of pages & 32 \\
\hline Email address corresponding author & djvandijk@few.eur.nl \\
\hline Address & Erasmus Research Institute of Management (ERIM) \\
& Rotterdam School of Management / Rotterdam School of \\
& Economics \\
& Erasmus Universiteit Rotterdam \\
& P.O. Box 1738 \\
& 3000 DR Rotterdam, The Netherlands \\
& Phone: $\quad+31104081182$ \\
& Fax: $\quad+31104089640$ \\
& Email: info@erim.eur.nl \\
& Internet: $\quad$ www.erim.eur.nl \\
\hline
\end{tabular}

Bibliographic data and classifications of all the ERIM reports are also available on the ERIM website: www.erim.eur.nl 


\section{ERASMUS RESEARCH INSTITUTE OF MANAGEMENT}

\section{REPORT SERIES}

\section{RESEARCH IN MANAGEMENT}

\begin{tabular}{|c|c|c|}
\hline \multicolumn{3}{|c|}{ BIBLIOGRAPHIC DATA AND CLASSIFICATIONS } \\
\hline Abstract & \multicolumn{2}{|c|}{$\begin{array}{l}\text { We examine competing explanations, based on risk and behavioral models, for the profitability of } \\
\text { stock selection strategies in emerging markets. We document that both emerging market risk } \\
\text { and global risk factors cannot account for the significant excess returns of selection strategies } \\
\text { based on value, momentum and earnings revisions indicators. The findings for value and } \\
\text { momentum strategies are consistent with the evidence from developed markets supporting } \\
\text { behavioral explanations. In addition, for value stocks, the most important behavioral bias } \\
\text { appears to be related to underestimation of long-term growth prospects, as indicated by overly } \\
\text { pessimistic analysts' earnings forecasts and above average earnings revisions for longer post- } \\
\text { formation horizons and by quite rapidly improving earnings growth expectations. Furthermore, } \\
\text { we find that overreaction effects play a limited role for the earnings revisions strategy, as there is } \\
\text { no clear return reversal up until five years after portfolio formation, setting this strategy apart } \\
\text { from momentum strategies. }\end{array}$} \\
\hline \multirow{3}{*}{$\begin{array}{l}\text { Library of Congress } \\
\text { Classification } \\
\text { (LCC) } \\
\text { LCC Webpage }\end{array}$} & \multicolumn{2}{|c|}{ Mission: HF 5001-6182 } \\
\hline & \multicolumn{2}{|c|}{ Programme: HF 4001-4280.7 } \\
\hline & Paper: HF 4529 & Portfolio management Finance \\
\hline \multirow{4}{*}{$\begin{array}{l}\text { Journal of Economic } \\
\text { Literature } \\
\text { (JEL) } \\
\text { JEL Webpage } \\
\end{array}$} & \multicolumn{2}{|l|}{ Mission: M } \\
\hline & \multicolumn{2}{|l|}{ Programme : G 3} \\
\hline & Paper: G 11 & Portfolio choice \\
\hline & G 15 & International Financial markets \\
\hline \multicolumn{3}{|c|}{ Gemeenschappelijke Onderwerpsontsluiting (GOO) } \\
\hline \multirow[t]{3}{*}{ Classification GOO } & \multicolumn{2}{|l|}{ Mission: 85.00} \\
\hline & \multicolumn{2}{|l|}{ Programme: 85.30} \\
\hline & Paper: 85.33 & beleggingsleer \\
\hline \multirow[t]{3}{*}{ Keywords GOO } & \multicolumn{2}{|c|}{ Mission: Bedrijfskunde / Bedrijfseconomie } \\
\hline & \multicolumn{2}{|c|}{ Programme: Financieel management, besliskunde } \\
\hline & \multicolumn{2}{|c|}{ Paper: risico's, nic's, portfolio-analyse } \\
\hline Free keywords & \multicolumn{2}{|c|}{ value, momentum, earnings revisions, risk, behavioral models, overreaction, underreaction. } \\
\hline
\end{tabular}




\title{
The Success of Stock Selection Strategies in Emerging Markets: Is it Risk or Behavioral Bias?*
}

\author{
Jaap van der Hart ${ }^{\dagger}$ \\ Emerging Markets Team \\ Robeco Group
}

\author{
Gerben de Zwart $\ddagger$ \\ Department of Quantitative Research \\ Robeco Group
}

\author{
Dick van Dijk ${ }^{\S}$ \\ Econometric Insitute \\ Erasmus University Rotterdam
}

February 2005

\begin{abstract}
We examine competing explanations, based on risk and behavioral models, for the profitability of stock selection strategies in emerging markets. We document that both emerging market risk and global risk factors cannot account for the significant excess returns of selection strategies based on value, momentum and earnings revisions indicators. The findings for value and momentum strategies are consistent with the evidence from developed markets supporting behavioral explanations. In addition, for value stocks, the most important behavioral bias appears to be related to underestimation of long-term growth prospects, as indicated by overly pessimistic analysts' earnings forecasts and above average earnings revisions for longer post-formation horizons and by quite rapidly improving earnings growth expectations. Furthermore, we find that overreaction effects play a limited role for the earnings revisions strategy, as there is no clear return reversal up until five years after portfolio formation, setting this strategy apart from momentum strategies.
\end{abstract}

JEL Classification: G11, G15

Keywords: value, momentum, earnings revisions, risk, behavioral models, overreaction, underreaction.

${ }^{*}$ We thank participants at the Inquire Europe meeting held in Prague, October 2004, for useful comments and suggestions. We thank Willem Jellema for excellent assistance in collecting the data.

${ }^{\dagger}$ Robeco Group, P.O. Box 973, 3000 AZ, Rotterdam The Netherlands, email: j.m.van.der.hart@robeco.nl

${ }^{\ddagger}$ Robeco Group, P.O. Box 973, 3000 AZ, Rotterdam The Netherlands, email: g.j.de.zwart@robeco.nl

${ }^{\S}$ Econometric Institute, Erasmus University Rotterdam, P.O. Box 1738, NL-3000 DR Rotterdam, The Netherlands, email: djvandijk@few.eur.nl (corresponding author) 


\section{Introduction}

Research in emerging markets finance has been rapidly expanding over the past two decades, see Bekaert and Harvey $(2002,2003)$ for comprehensive surveys of the past, present and future of the area. Relatively few studies exist that investigate individual stock selection for emerging markets, see Claessens, Dasgupta and Glen (1998), Fama and French (1998), Patel (1998), Achour et al. (1998, 1999a,b,c), Rouwenhorst (1999), Barry et al. (2002), and van der Hart, Slagter and van Dijk (2003). The general conclusion from these studies appears to be that stock selection strategies that work well in developed markets also generate significant outperformance in emerging markets. The most recent analysis by van der Hart et al. (2003), based on almost 3000 securities from 32 countries and an extensive set of selection strategies, finds that in internationally diversified (but country-neutral) portfolios, value stocks outperform growth stocks, past winners (based on six-month momentum) outperform past losers, and stocks with (relatively) high analysts' earnings revisions outperform stocks with low revisions.

There is an ongoing debate concerning the underlying reasons for (or the appropriate interpretation of) the profitability of value, momentum and revisions strategies. Roughly speaking, on the one hand, the excess returns of these stock selection strategies are believed to be compensation for risk involved, whereas on the other hand they are attributed to behavioral biases, with investors either under- or overreacting to the release of new firm-specific information. To add to this discussion, in this paper we perform an 'out-of-sample' test of these competing explanations, by examining whether they can account for the profitability of stock selection strategies in emerging markets. As most research in this area has been conducted for developed markets, emerging markets provide an excellent opportunity to study the source of return premiums on a relatively independent sample.

We find that both emerging market risk and global factor risk (using a fourfactor model including market, book-to-market, size and momentum factors) cannot explain the excess returns of the selection strategies in emerging markets. Relatively few factor loadings are found to be significant, while excess returns of the strategies remain of the same magnitude and significant after accounting for risk. We find more convincing evidence in favor of behavioral explanations for value and momentum anomalies put forward in the context of developed markets. In addition, we present new results supporting an underrreaction effect for the earnings revisions strategy.

For value strategies, our findings are in accordance with the underreaction or extrapolation hypothesis developed in Lakonishok, Shleifer and Vishny (1994), which 
posits that the outperformance of value stocks arises because investors systematically underestimate the earnings growth prospects of such stocks. We find that the actual earnings growth of value stocks in emerging markets equals the average earnings growth after just a few years, indicating that the difference in valuation between value and growth stocks indeed is not justified by subsequent earnings developments. At the same time, we find that the evidence for emerging markets is also in line with the results of Doukas, Kim and Pantzalis (2002), who document that analysts in fact are more optimistic about value than growth stocks, seemingly contradicting the behavioral interpretation of Lakonishok et al (1994). We suggest a possible reconciliation for these contrasting views, based on the idea that the most important behavioral bias is related to underestimation of long term earnings growth prospects for value stocks. This is supported by our finding that analysts' forecast errors (defined as actual earnings minus the corresponding earnings forecast) and earnings revisions for value stocks are below average only up until approximately one year after portfolio formation. After this initial period, analysts indeed become less optimistic about value than growth stocks. In addition, we observe that the expected earnings growth for value stocks improves quite rapidly and exceeds the average expected growth within two years after portfolio formation.

For the momentum strategy, we find elements of both underreaction and overreaction, in agreement with the evidence from developed markets. On the one hand, stocks with high past returns have higher earnings forecast errors and earnings revisions for about one year after portfolio formation, indicating an underreaction effect, similar to the findings of Chan, Jegadeesh and Lakonishok (1996) for the US. On the other hand, in line with Jegadeesh and Titman (2001) and Nagel (2002), we also find that momentum strategies have a pronounced reversal in excess returns between three and five years after portfolio formation, indicating an overreaction effect.

For the earnings revisions strategy, our results lend unequivocal support to an underreaction explanation. In line with the US evidence of Chan et al. (1996) and our own findings for the emerging markets momentum strategy, stocks with high past earnings revisions continue to have earnings revisions (and earnings forecast errors) above average for about one year after portfolio formation. Contrary to the momentum strategy, we find no return reversal for the earnings revisions strategy up until five years after portfolio formation, indicating a distinct difference between these strategies. To the best of our knowledge, return reversals for earnings revisions strategies have not been examined before, even for developed markets.

The plan of the paper is as follows. Section 2 describes the data and stock 
selection strategies. Section 3 summarizes the results concerning their profitability and the robustness thereof. Sections 4 and 5 explore the competing explanations for the excess returns of the strategies in terms of risk and behavior, respectively. Finally, Section 6 concludes.

\section{Methodology}

\subsection{Data}

Stock returns, earnings and book value data are drawn from the S\&P/IFC Emerging Markets database. Monthly total stock returns are measured in US dollars, and account for dividends, stock splits and other capital adjustments, cf. Rouwenhorst (1999). The returns contain some extreme observations, which are at least partly due to data errors. To avoid a potentially disrupting impact from large data errors, we compare the total returns from $\mathrm{S} \& \mathrm{P} / \mathrm{IFC}$ with corresponding total returns from the Factset Pricing database, as well as with price returns from both sources. In case of extreme return observations with large differences between the data sources, we use the smallest absolute value to err on the side of caution. In addition, we cap monthly returns at $300 \%$ or $150 \%$, depending on whether or not the S\&P/IFC data is confirmed by Factset Pricing.

We exclude stocks that are not included in the IFC Investable Composite index ${ }^{1}$ and stocks that have a real investable market value less than 100 million in December 1998 US dollars, applying a 10 percent annual inflation rate. This makes the selection strategies feasible for a large international investor, while it also mitigates the problem of survivorship bias in the Emerging Markets database, due to backfilled data for some countries in the period before inclusion in the IFC Investable Composite index, see Harvey (1995) for detailed discussion. In addition, we omit countries with less than four stocks and countries for which the data necessary for

\footnotetext{
${ }^{1}$ The IFC Investable Composite Index consists of stocks from the following countries, with the first month of inclusion in parenthesis. In case two months are provided, the second indicates the last month of inclusion. Latin America: Argentina (Dec 1988), Brazil (Dec 1988), Chile (Dec 1988), Colombia (Feb 1991 - Nov 2001), Mexico (Dec 1988), Peru (Jan 1994), Venezuela (Jan 1990 - Nov 2001); Asia: China (Oct 1995), India (Nov 1992), Indonesia (Sep 1990), Korea (Jan 1992), Malaysia (Dec 1988), Pakistan (Mar 1991 - Nov 2001), Philippines (Dec 1988), Sri Lanka (Jan 1994 - Nov 2001), Taiwan (Jan 1991), Thailand (Dec 1988); Europe: Czech Republic (Jan 1996), Greece (Dec 1988 - Apr 2001), Hungary (Apr 1994), Poland (Apr 1994), Portugal (Dec 1988 - Mar 1999), Russia (Nov 1997), Slovakia (Nov 1997 - Nov 2001), Turkey (Aug 1989); Africa \& Middle East: Egypt (Nov 1997), Israel (Dec 1996), Jordan (Dec 1988 - Nov 2001), Morocco (Nov 1997), South Africa (Apr 1995), and Zimbabwe (Apr 1994 - Nov 2001). Malaysia was not included during the period Oct 1998 - Oct 1999.
} 
the particular selection strategy is available for less than 30 percent of the stocks. We discard these "small" countries because the selection strategies construct local return factor portfolios from the top and bottom 15 percent stocks in each country separately.

The data from S\&P/IFC are supplemented with analysts' earnings forecasts from the Institutional Brokers Estimate System (IBES). These are used to compute earnings revisions, defined as the number of analysts with upward revisions minus the number of analysts with downward revisions divided by the total number of analysts providing an earnings forecast in a particular month, following Achour et al. (1998).

Combining the different databases, we implement the stock selection strategies described below over the period from December 1988, the inception month of the IFC Investable Composite index, until June 2004. The number of stocks that are used for testing the strategies starts at about 100 in December 1988, grows quite rapidly to about 700 in 1994 and varies between 600 and 900 stocks in the remaining years.

\subsection{Stock Selection Strategies}

We investigate stock selection strategies based on the value indicators book-tomarket $(\mathrm{B} / \mathrm{M})$ and earnings-to-price $(\mathrm{E} / \mathrm{P})$, based on momentum as measured by the total return over the previous six months (6MR), and based on analysts' earnings revisions, measured by the past three-month average earnings revisions for the current fiscal year (ER FY1). The methodology underlying the portfolio construction is described below.

All strategies are applied without a delay between the moment of ranking and the moment of portfolio formation. As the IFC and IBES databases contain data as published, all sorting characteristics would have been available to investors at the time of ranking and, hence, the selection strategies do not use any future information. $^{2}$ At the beginning of each month, we rank the stocks by country on each of the above characteristics in descending order. For each country in the sample, equally weighted 'top' and 'bottom' portfolios are formed from the 15 percent

\footnotetext{
${ }^{2}$ Apart from worries about the timely availability of the sorting variables, another reason to implement momentum strategies with a delay (usually of one-month) is to attenuate the effects of bid-ask bounce, see Achour et al. (1998) and Rouwenhorst (1999), among others. Because of the minimum capitalization requirement that we impose, the smallest, and probably least liquid, stocks are not included in our sample and, hence, bid-ask bounce is less important at the monthly frequency. Therefore, we also implement the momentum strategies without delay, such that, for example, the 6-month momentum factor that is used to rank the stocks at the beginning of month $t$ is based on the average return from the beginning of month $t-6$ to the end of month $t-1$.
} 
stocks ranked highest and lowest, respectively. ${ }^{3}$ These country portfolios are then combined into internationally diversified portfolios, in which each stock receives an equal weight. Each month, new portfolios are constructed which are held for a period of six months. After formation, the portfolios are not rebalanced, except to account for stocks leaving the IFC Investables index. These stocks exit the relevant portfolio and the weights of the remaining stocks are adjusted proportionally. As we construct new portfolios every month and use a six-month holding period, at any point in time the strategies effectively hold stocks from six portfolios, each formed one month apart. To handle the problems concerned with overlapping returns, we calculate monthly returns for a particular strategy as the average of the returns on the six similar portfolios, cf. Jegadeesh and Titman $(1993,2001)$ and Rouwenhorst (1998).

\section{Profitability of Stock Selection Strategies}

In this section, we evaluate the performance of the stock selection strategies based on value, momentum and earnings revisions. Table 1 shows the average monthly returns during the six-month holding period for the top portfolio, an equally weighted index consisting of all stocks in the relevant sample (EWI) and the bottom portfolio, as well as the excess returns of the top portfolio versus the equally weighted index (TMI) and versus the bottom portfolio (TMB).

All four selection strategies prove to be successful, in the sense that the excess returns of the top portfolio are positive and strongly statistically significant. Compared to the EWI, the average monthly excess returns of the top portfolio vary from $0.24 \%$ for the earnings revisions strategy to $0.53 \%$ for the B/M strategy. The average returns for the top versus bottom portfolio range between $0.59 \%$ and $0.74 \%$ per month, with the highest average return for the momentum strategy and the lowest again for the earnings revisions strategy. These magnitudes of the strategies' excess returns are similar to those found in van der Hart et al. (2003), as well as the results reported in Rouwenhorst (1999) for B/M and momentum and in Achour et al. (1998) for earnings revisions.

\footnotetext{
${ }^{3}$ Stocks are selected in each country separately to avoid any implicit country allocation. We examine the added value of country selection by ranking stocks globally and forming equally weighted portfolios consisting of the top and bottom 15 percent stocks in this alternative ranking. We find that such 'global ranking' adds considerably to the profitability of the stock selection strategies. The excess returns due to country selection are, however, much more volatile than the excess returns due to stock selection.
} 
It is worth noting that in case the performance of the top portfolio is measured relative to the bottom portfolio, the excess returns generated by the $\mathrm{B} / \mathrm{M}, \mathrm{E} / \mathrm{P}$ and $6 \mathrm{MR}$ strategies are very close. In contrast, when the top portfolio is compared with the EWI, the B/M strategy markedly outperforms the other two strategies, by approximately $0.2 \%$ per month. Hence, for the E/P and $6 \mathrm{MR}$ strategies a substantial part of the profits from a zero-investment strategy based on the TMB portfolio would come from the sell side, while this is not the case for the B/M strategy. Because of short sales restrictions in emerging markets, implementing the TMB strategy as a zero-investment strategy may not be feasible in practice; see Bekaert and Urias (1996), Alexander (2000) and and De Roon, Nijman and Werker (2001). The E/P and 6-month momentum strategies therefore are mostly relevant for avoiding or underweighting 'bad' stocks, see Achour et al. (1998).

To analyze the stability of the strategies' performance, Figure 1 plots 12 -month moving average excess returns of the top portfolios relative to the EWI, while Table 2 shows the TMI excess returns for three five-year subsample periods. All strategies have positive excess returns in all three subperiods, and most excess returns are statistically significant. For the B/M strategy, the average excess return decreased considerably over time, from $0.84 \%$ over the period July 1989-June 1994 to 0.39\% over the period July 1994-June 2004. In contrast, for the E/P and earnings revisions strategies the excess returns were quite stable across sub-periods, while the performance of the momentum strategy even improved notably over time. Finally, Figure 1 reveals that the $\mathrm{B} / \mathrm{M}$ strategy was heavily affected by the Asia crisis in 1997 during which it underperformed relative to the EWI, while the momentum and earnings revisions strategies had negative excess returns following the Russia crisis in 1998. In contrast, the performance of the E/P strategy was affected to a much lesser extent during these periods.

In the following sections we explore the different explanations for the apparent success of stock selection strategies in emerging markets as documented above, in terms of exposure to risk and in terms of behavioral biases.

\section{Risk-Based Explanations for the Profitability of Selection Strategies}

If the selection strategies tended to select stocks with high sensitivity to overall movements in emerging equity markets, their excess returns would possibly only be 
a reward for this additional risk. To examine this possibility, we use the regression

$$
R_{p, t}-R_{f, t}=\alpha+\beta_{\mathrm{EM}}\left(R_{\mathrm{EM}, t}-R_{f, t}\right)+\varepsilon_{t}
$$

where $R_{p, t}$ is the monthly return on the equally weighted top or bottom portfolio of a particular strategy, $R_{\mathrm{M}, t}$ is the corresponding benchmark return on the equally weighted index consisting of all emerging market stocks in our sample (EWI), and $R_{f, t}$ is the 1-month US T-bill rate.

The estimation results presented in Table 3 show that for all strategies the betas of the top and bottom portfolios are close to one. Only the B/M strategy appears to bear higher 'emerging market risk', as the betas of its top and bottom portfolios are significantly greater and less than one, respectively. We find significant deviations from one for the betas of portfolios of the other three strategies as well, but these are of the opposite sign as expected under a risk-based explanation. For the E/P and $6 \mathrm{MR}$ strategies, the betas of their bottom portfolios are significantly greater than one, while the beta of the top portfolio of the earnings revisions strategy is significantly less than one. The excess returns after correcting for emerging market risk, as measured by the intercept $\alpha$ in (1), remain statistically significant for all portfolios except the bottom portfolio of the B/M strategy. They in fact are very close to the raw excess returns reported in Table 1. In sum, the excess returns of the stock selection strategies do not appear to be compensation for excess emerging market risk.

Next, we investigate whether the return and risk properties of the selection strategies depend upon whether the emerging markets as a whole go up or down. This is motivated by the finding of Ang, Chen, and Xing (2004) that the cross-section of US stock returns reflects a premium for downside risk; see also Estrada (2000, 2001) for a downside risk analysis in emerging markets. This is reflected in the model

$$
\begin{aligned}
R_{p, t}-R_{f, t}=\alpha^{-} I_{\left\{R_{\mathrm{EM}, t}-R_{f, t}<0\right\}}+\beta_{\mathrm{EM}}^{-}\left(R_{\mathrm{EM}, t}-R_{f, t}\right) I_{\left\{R_{\mathrm{EM}, t}-R_{f, t}<0\right\}}+ \\
\alpha^{+} I_{\left\{R_{\mathrm{EM}, t}-R_{f, t} \geq 0\right\}}+\beta_{\mathrm{EM}}^{+}\left(R_{\mathrm{EM}, t}-R_{f, t}\right) I_{\left\{R_{\mathrm{EM}, t}-R_{f, t} \geq 0\right\}}+\varepsilon_{t},
\end{aligned}
$$

where the returns $R_{p, t}, R_{\mathrm{EM}, t}$ and $R_{f, t}$ are defined as before, and $I_{\{A\}}$ denotes the indicator function for the event $A$, such that $I_{\{A\}}=1$ if $A$ occurs and 0 otherwise. Hence, $\beta_{E M}^{+}$and $\beta_{E M}^{-}$measure emerging market risk when the market goes up and down, respectively, while $\alpha^{+}$and $\alpha^{-}$measure the corresponding excess returns. Table 4 presents the results from estimating (2) for the top and bottom portfolios of the four strategies. It is seen that the difference between upside and downside betas generally is very small, indicating that the strategies do not bear excessive downside (or upside) emerging market risk. This being said, we do find more substantial 
differences in excess returns in up and down markets. For example, $\alpha^{-}$and $\alpha^{+}$for the top portfolio of the B/M strategy are equal to $-0.05 \%$ and $0.65 \%$, respectively, indicating that the outperformance of this strategy is attained completely in months when emerging markets as a whole go up. This contrasts quite sharply with results for the US in Lakonishok et al. (1994), who document that value stocks outperform glamour stocks especially in negative market return months. For the E/P and earnings revisions strategies, we also find that excess returns of the top portfolio relative to the market are larger in positive market return months. Note, however, that for the E/P strategy the bottom portfolio also performs relatively better in upward markets, such that the outperformance of the top versus bottom portfolio is not sensitive to the direction of the overall market. The same holds for the momentum strategy, although in that case we find that $\left|\alpha^{+}\right|<\left|\alpha^{-}\right|$. In sum, the evidence in Table 4 indicates that the selection strategies do not expose investors to greater downside (or upside) emerging market risk.

Finally, we consider the possibility that the excess returns are rewards for exposures to global risk factors by using the four-factor regression model developed by Fama and French $(1993,1996)$ and Carhart (1997). This model explains portfolio returns in excess of the risk-free rate $\left(R_{p, t}-R_{f, t}\right)$ by sensitivities to the excess return on the market portfolio $\left(R_{\mathrm{M}, t}-R_{f, t}\right)$ and the difference between the returns on portfolios of stocks with high and low book-to-market values $\left(R_{\mathrm{HML}, t}\right.$, HML $=$ High-Minus-Low), on portfolios of stocks with small and large market capitalization $\left(R_{\mathrm{SMB}, t}, \mathrm{SMB}=\right.$ Small-Minus-Big), and on portfolios of stocks with high and low momentum $\left(R_{\mathrm{UMD}, t}, \mathrm{UMD}=\mathrm{Up}\right.$-Minus-Down $)$. That is, the model is given by

$$
R_{p, t}-R_{f, t}=\alpha+\beta_{\mathrm{M}}\left(R_{\mathrm{M}, t}-R_{f, t}\right)+\beta_{\mathrm{HML}} R_{\mathrm{HML}, t}+\beta_{\mathrm{SMB}} R_{\mathrm{SMB}, t}+\beta_{\mathrm{UMD}} R_{\mathrm{UMD}, t}+\varepsilon_{t} .
$$

The four-factor model is estimated with $R_{p, t}$ being the returns on the top and bottom portfolios in the different strategies, the returns on the equally weighted index of the corresponding samples of emerging market stocks (EWI), and the TMI and TMB excess returns. For the TMI and TMB excess return regressions, the risk-free interest rate is not included on the left-hand side of (3). As proxies for the global risk factors, we use the US returns data available on the website of Kenneth French. ${ }^{4}$

The estimation results in Table 5 show a number of interesting features. First, the estimates of $\beta_{\mathrm{M}}$ are significantly less than one for all top and bottom portfolios and indexes of emerging market stocks. This finding can probably be attributed to

\footnotetext{
${ }^{4}$ http://mba.tuck.dartmouth.edu/pages/faculty/ken.french/data_library.html
} 
the fact that the emerging markets were not completely liberalized and integrated with global equity markets during our sample period, especially during the first part; see Bekaert and Harvey (2000a,b) and Edison and Warnock (2003), among others. ${ }^{5}$

Note that for all selection strategies the betas for the top portfolios are not significantly greater than the betas for the corresponding EWI and bottom portfolios. The resulting estimates of beta when the excess returns of the top portfolio relative to the EWI or bottom portfolio are used as dependent variable therefore are close to zero for all selection strategies considered. Second, the returns for the emerging market portfolios are positively correlated with the returns for small versus big stocks, as evidenced by the positive and statistically significant estimates of $\beta_{\mathrm{SMB}}$ for the top, index and bottom portfolios of all strategies. In contrast, the emerging market portfolios are virtually insensitive to the HML and UMD factors. The estimates of $\beta_{\mathrm{HML}}$ are never significant (at the two-sided 5\% significance level) for the top, EWI and bottom portfolios, while the estimate of $\beta_{\mathrm{UMD}}$ is significant only for the bottom portfolio of the momentum strategy. Third, the sensitivities of the TMI and TMB excess returns are never significantly different from zero, except for the SMB and UMD factors in case of the B/M and momentum strategies, respectively. Fourth, and perhaps most important, the estimated intercepts $\alpha$ for the TMI and TMB excess returns are significantly different from zero for all strategies, and are very close to the raw excess returns reported in Table 1. The only exception appears to be the momentum strategy, for which a sizeable part of the excess return is accounted for by global momentum risk. Overall, however, global book-to-market, size and momentum risk factors cannot explain the outperformance of stock selection strategies in emerging markets. This corroborates the results obtained by Rouwenhorst (1999) using a two-factor model with only the HML factor included next to the market portfolio return.

\footnotetext{
${ }^{5}$ van der Hart et al. (2003) investigate the effects of financial market liberalization on the performance of stock selection strategies. Estimating the four-factor model separately for returns on portfolios consisting of stocks from liberalized or non-liberalized countries only, no significant differences in factor loadings are found. Alternatively, estimating (3) with a five-year rolling sample indicated that liberalization did affect the risk properties of the selection strategies, in the sense that the estimates of $\beta_{\mathrm{M}}$ show a tendency to increase over time. The exposures to the other factors in the model, as well as the intercept $\alpha$, also show substantial variation. However, there are no easily discernible patterns. For example, it is not the case that $\alpha$ gradually declines over time or becomes insignificant. A more thorough investigation of this issues, using models that allow the factor loadings to vary with conditioning variables, as in Ferson and Harvey (1999), or that allow for time-varying integration, as in Bekaert and Harvey $(1995,1997)$, is interesting for further research.
} 


\section{Behavioral Explanations for the Profitability of Selection Strategies}

In this section we explore whether behavioral explanations can account for the success of the stock selection strategies in emerging markets. We discuss value strategies and momentum and earnings revisions strategies separately. Although momentum and revisions strategies prove to have different features in some respect, they are treated together as the same characteristics are examined.

\section{$5.1 \quad$ Value Strategies}

Lakonishok et al. (1994) provide a behavioral explanation for the significant excess returns of value strategies. They argue that investors are excessively pessimistic (optimistic) about future earnings growth of value (growth) stocks, because they extrapolate past growth rates too far into the future. Using a sample of US stocks and various measures of growth, including earnings, Lakonishok et al. (1994) demonstrate that glamour stocks grow much faster than value stocks before portfolio formation. During the post-formation period, earnings growth rates continue to be lower for value stocks than for glamour stocks for the first two years, but this pattern is reversed over the following three years, resulting in approximately equal growth rates over the complete five-year period. Hence, actual post-formation earnings growth of value stocks relative to growth stocks turns out to be substantially higher than what they were during the pre-formation period or than what investors expected them to be according to multiples such as the $\mathrm{E} / \mathrm{P}$ ratio. Buying and selling stocks with low and high expected earnings growth, respectively, then produces excess returns.

To examine whether this behavioral explanation may account for the excess returns of the value strategies in emerging markets, we examine how earnings of the stocks in the $\mathrm{B} / \mathrm{M}$ and $\mathrm{E} / \mathrm{P}$ top portfolios and in the complete sample of stocks develop after portfolio formation. Figure 2 shows the earnings yield, defined as the average earnings as a percentage of the initial invested capital, for the first five years after portfolio formation.

By construction, for the $\mathrm{E} / \mathrm{P}$ portfolio the earnings yield is higher at formation date. Over the next 18 to 24 months, average earnings of the E/P top portfolio fall, whereas earnings of the average stock in the sample increase gradually. However, the earnings level of the value portfolio remains above that of the average stock in the sample. More importantly, after approximately 24 months earnings growth rates are about equal, such that the difference in earnings levels remains fairly constant 
thereafter. For the B/M strategy, we find similar results. Although the difference in initial earnings yield is much smaller, we do find negative growth during the first 18 months after portfolio formation. This is followed by above average growth in the subsequent period, such that after three and a half years the stocks in the $\mathrm{B} / \mathrm{M}$ portfolio again have higher earnings levels than the average stock. The improvement in earnings growth may lead to valuation ratios for the value portfolios that are more in line with the market average. This is indeed the case. The average fall in earnings is more than compensated for by a rise in the stock price, leading to an improvement in the price-to-earnings ratio. Concluding, the differences in valuation ratios between value and growth stocks are not justified by subsequent earnings developments. After two years, the earnings growth rate of value stocks is equal to the growth rate of the average stock. Hence, our findings for value strategies in emerging markets correspond with the evidence for this behavioral explanation in Lakonishok et al. (1994).

More recently, Doukas et al. (2002) argue that the results of Lakonishok et al. (1994) do not imply that investors actually underestimate the growth prospects for value stocks. To the contrary, using analysts' earnings forecasts for the next three years, they find that analysts are on average more (over)optimistic for value stocks than for growth stocks. In addition, they find that value stocks have larger negative revisions of earnings estimates than growth stocks. Based on this evidence they conclude that the superior return performance of value stocks cannot be explained by excessive pessimism about future earnings growth.

In our view, the evidence from Doukas et al. (2002) is not necessarily at odds with the evidence from Lakonishok et al. (1994). It may be argued that long-term developments are most important for equity valuation and that, hence, the three year post-portfolio formation period considered by Doukas et al. (2002) is too short. Analysts might overestimate the short-run earnings developments of value stocks, but at the same time underestimate the potential for earnings growth to revert to the mean at longer horizons. The improvement in the earnings growth rate and the strong recovery in $\mathrm{P} / \mathrm{E}$ ratio for value stocks discussed above indicate that their long-term earnings prospects improve sharply after just a few years. We put this hypothesis to the test using analysts' earnings forecast errors, earnings revisions and earnings growth forecasts, during the five years after portfolio formation.

For an individual stock, the earnings forecast error in month $t$, denoted $F E_{t}$, is defined only once a year, namely eight months prior to fiscal year end. In that case, $F E_{t}$ is equal to the difference between the actual earnings in the current fiscal year 
$\left(\mathrm{FY}_{t+8}\right)$ and the consensus analysts' forecast issued in month $t\left(\mathrm{FY}_{t}\right)$, expressed as percentage of the stock price at the time of the forecast $\left(P_{t}\right)$; that is $\mathrm{FE}_{t}=$ $100 \times\left(\mathrm{FY0}_{t+8}-\mathrm{FY} 1_{t}\right) / P_{t}$. We define the consensus forecast as the median forecast reported by IBES. The eight month horizon is adopted from Easterwood and Nutt (1999) and Doukas et al. (2002) and is chosen to ensure that the previous year's annual report was available to analysts at the time they issued their forecasts. We also follow Easterwood and Nutt (1999) in eliminating observations for which the forecast error is greater than 100 in absolute value. Figure 3 plots the three-month moving average mean earnings forecast errors for the top and bottom portfolios of the value strategies. Note that these graphs truly concerns the post-formation period, in the sense that the leftmost point corresponds with the error for analysts' earnings forecasts issued in the first three months following portfolio formation. For the $\mathrm{B} / \mathrm{M}$ strategy, we observe that immediately following portfolio formation, earnings forecast errors for the top and bottom portfolios are substantially below and above average, respectively. ${ }^{6}$ In fact, this continues to be the case until 18 months after portfolio formation. Hence, analysts indeed appear to be more optimistic about the earnings prospects of value than growth stocks, as reported in Doukas et al. (2002). In the remaining post-formation period, however, the pattern is reversed. While the earnings forecast error for growth stocks remains close to the average, it becomes substantially larger than average for value stocks, implying that analysts are relatively pessimistic about value stocks' earnings in the longer term. For the $\mathrm{E} / \mathrm{P}$ strategy, we observe a similar reversal in earnings forecast errors, although in this case the error for growth stocks dips below average around 18 months after portfolio formation, while for value stocks it remains at par. The implication is however the same, namely that analysts are relatively optimistic (pessimistic) about growth (value) stocks.

The above analysis is corroborated by the development of analysts' earnings

\footnotetext{
${ }^{6}$ Notice that for the EWI, the forecast error is negative for each month in the post-formation period. This demonstrates the notion that analysts are (too) optimistic about future earnings for the average stock in the sample. In addition to systematic positive bias in analysts' earnings forecasts (see Easterwood and Nutt (1999) for recent evidence), the extent of this bias has also been found to be predictable from observable firm characteristics, see Abarbanell and Bernard (1992), among others. Analysts' forecasts are therefore usually dismissed as being irrational or inaccurate. A recent study by Lim (2001) shows that positively and predictably biased forecasts may in fact be optimal if the incentive structure of analysts is taken into account. If analysts balance forecast accuracy and improved access to management information, such biased forecasts are rational. Furthermore, Hong and Kubik (2003) document that optimistic analysts promoting stocks are more likely to experience favorable job separations. Hence, career concerns may also lead to upward biases in analysts' forecasts.
} 
revisions after portfolio formation, as shown in Figure 4. Analysts' revisions are more negative for stocks in the $\mathrm{B} / \mathrm{M}$ and $\mathrm{E} / \mathrm{P}$ top portfolios until 10 and 15 months after portfolio formation, respectively, again indicating that they were too optimistic about the earnings prospects for value stocks. ${ }^{7}$ For the $\mathrm{B} / \mathrm{M}$ strategy, earnings revisions for these stocks rise (substantially) above average between one and four years after portfolio formation. During roughly the same period, earnings revisions for growth stocks fall below average. For the E/P strategy, the differences are smaller, but the earnings revisions for the top portfolio do remain above the revisions for the bottom portfolio during the period between 15 and 48 months after portfolio formation.

Finally, the improvement in earnings prospects is also confirmed by looking at the developments of the earnings growth expected by analysts after portfolio formation for each of the portfolios. Figure 5 depicts the difference between the consensus earnings forecast for the next fiscal year (FY2) versus the most recent actual earnings $(\mathrm{FY} 0)$. Like in the earnings figures in Figure 2, the expected earnings change is normalized by calculating this number as a percentage of the initially invested capital at portfolio formation. For the $\mathrm{E} / \mathrm{P}$ strategy, the expected earnings change is much lower for the top portfolio, as to be expected. However, it reverts to the mean quite rapidly. The expected earnings change for the top portfolio exceeds those for the equally weighted index and for the bottom portfolio within two and three years, respectively. For the B/M strategy, the starting point differs as the expected earnings change at portfolio formation is already slightly higher for the top portfolio. What is the same, however, is that the expected earnings change increases more strongly for the top portfolio. The growth characteristics of expensive stocks based on $\mathrm{E} / \mathrm{P}$ and $\mathrm{B} / \mathrm{M}$ appear to be rather short-lived.

Concluding, just like Lakonishok et al. (1994), we find that the relative cheapness of value stocks is not justified by subsequent earnings developments. For value stocks, earnings as percentage of the initial investment remain well above the averages for the complete sample and for growth stocks, while both the actual earnings growth and its forecast revert to the mean quite rapidly. Like Doukas et al. (2002), we do find that analysts appear too optimistic about the earnings prospects for value stocks in the short term. We also find that this reverses in the longer term as value stocks have above average earnings forecast errors and earnings revisions after about

\footnotetext{
${ }^{7}$ Notice that for the EWI, forecast revisions are negative for each month in the post-formation period, confirming that analysts are (too) optimistic about future earnings for the average stock in the sample.
} 
one year after portfolio formation. This indicates that analysts are too pessimistic about the long term growth perspectives for value stocks.

\subsection{Momentum and Earnings Revisions Strategies}

A number of studies have tested behavioral explanations for momentum strategies in developed markets (see amongst others Chan et al. (1996), Jegadeesh and Titman (2001), Lee and Swaminathan (2000), Hong, Lim and Stein (2000), Nagel (2002), and Cooper, Gutierrez and Hameed (2004)). Underreaction and overreaction effects are part of these explanations. In this section we investigate whether these effects are present in the emerging markets momentum strategy as well, by examining three variables that might serve as indicators for under- or overreaction: analysts' earnings revisions, analysts' forecast errors and cumulative excess returns after portfolio formation.

Chan et al. (1996) put forward a behavioral explanation for the profitability of momentum and earnings revisions strategies, based on the idea that financial markets respond only gradually to new information, to earnings-related news in particular. Using a sample of US stocks, they find empirical evidence that stocks with high price momentum or high past earnings revisions have higher returns around earnings announcements, higher earnings revisions and higher earnings surprises for some time after portfolio formation. Momentum and earnings revisions strategies thus are successful because they exploit the initial underreaction of investors to the information in past returns and past earnings revisions.

Figure 6 shows how earnings revisions for the top and bottom portfolios in the momentum and the earnings revisions strategies and for the complete sample of emerging market stocks develop during the five years after portfolio formation. For both strategies, earnings revisions of the top (bottom) portfolio remain higher (lower) than earnings revisions for the complete sample until 18 months after portfolio formation. ${ }^{8}$ This agrees with the behavioral explanation of Chan et al. (1996) that the market does not incorporate news in earnings revisions promptly.

Alternative interpretations of the observed pattern in earnings revisions are possible as well. For example, one can argue that analysts are slow in adjusting their estimates and that earnings revisions therefore are not a good proxy for market surprises. We therefore examine analysts' forecast errors, defined as before, in Figure 7. The patterns in this variable confirm the underreaction hypothesis: despite higher

\footnotetext{
${ }^{8}$ The difference in earnings revisions is significant for each of the first 12 months after portfolio formation, for both the earnings revisions strategy and the momentum strategy.
} 
past returns and earnings revisions, stocks in the top portfolios of the momentum and revisions strategies continue to show above average, and in fact positive forecast errors until more than a year after portfolio formation.

Behavioral models, such as the ones in Barberis, Shleifer and Vishny (1998), Daniel, Hirshleifer and Subrahmanyam (1998) and Hong and Stein (1999), imply that excess returns of momentum portfolios should become zero or negative after the initial holding period. These theoretical models do not offer any guidance, however, regarding the length of the post-holding period over which these return reversals should occur. To further support their underreaction hypothesis, Chan et al. (1996) show that there is no evidence of a return reversal during the first three years after portfolio formation. In contrast, Jegadeesh and Titman (2001), among others, find that a return reversal does occur when extending the post-portfolio formation period to five years. For emerging markets, Figure 8 shows the cumulative excess returns during the first five years after portfolio formation, both for the momentum and the earnings revisions strategies.

For the momentum strategy, we observe a return reversal for the top portfolio after approximately three years. Its magnitude is, however, not large enough to completely annihilate the excess returns within the five year period considered. However, the excess return on the bottom portfolio reverses after one year already, such that after three and a half years the bottom portfolio outperforms the equally weighted benchmark and after four years its cumulative performance is comparable to the top portfolio. Hence, although we do not observe a return reversal as strong as documented by Nagel (2002) for momentum strategies in the UK, we do find that four years after portfolio formation past winners and losers can no longer be distinguished. The results for the revisions strategy are rather different. High earnings revisions stocks continue to outperform the market average after the six-month holding period, and a return reversal does not occur during the first five years after portfolio formation.

Concluding, the momentum strategy seems to have elements of both overreaction and underreaction effects, as the analysts' earnings revisions and forecast errors suggest an underreaction, while the five-year post-formation returns suggest an overreaction. A possible solution may be found in Lee and Swaminathan (2000), who investigate the interaction between momentum and turnover, and find different behavior for high turnover momentum stocks versus low turnover momentum stocks in the US. Nagel (2002) finds similar results for the UK and relates them to implicit value effects. An interesting topic for further research would be to test these 
results for emerging markets. For the earnings revisions strategy, both the earnings revisions by analysts after portfolio formation as well as the five-year excess returns point towards an initial underreaction. This shows that the revisions strategy has different characteristics than the momentum strategy.

\section{Conclusions}

Stock selection strategies based on value, momentum and earning revisions prove to generate significant excess returns in emerging markets. In this paper, we investigate different explanations for the success of these strategies, using stocks included in the IFC Investable Composite Index over the period December 1988 - June 2004.

We find little if any evidence for risk-based explanations. The excess returns remain significant after correcting for (potentially different upside and downside) emerging market risk, as well as after correcting for global market risk, value, size and momentum factors. Only the performance of the momentum strategy can partly be attributed to a global momentum risk factor.

We do find that the emerging markets results are consistent with the evidence from developed markets concerning behavioral explanations. For value stocks, our findings are in accordance with an overreaction explanation, as the actual and expected earnings growth of these stocks reverts to the mean in a few years and the earnings as percentage of initial investment remains well above average. The overreaction explanation seems to be contradicted by the finding that value stocks have below average (and substantially negative) earnings forecast errors and earnings revisions up to a year after portfolio formation. As a possible solution we suggest that the most important behavioral bias could be related to underestimation of long-term growth rates for value stocks. This conjecture is supported by the observation that earnings forecast errors and earnings revisions for these stocks become above average for longer post-formation horizons and by the finding that estimated earnings growth becomes above average within two years after portfolio formation. For the momentum strategy, both underreaction and overreaction effects appear to be at work. High upward earnings revisions by analysts after portfolio formation suggest an initial underreaction. However, in the five-year post-formation period, we also observe a strong return reversal, indicating an overreaction effect. In contrast, the evidence does support an underreaction explanation for the earnings revisions strategy. Stocks with high past earnings revisions continue to have high upward earnings revisions for twelve months after portfolio formation, while there is no return reversal 
until at least five years after portfolio formation. As the earnings revisions strategy seems to have no or limited overreaction effects, this sets it apart from momentum strategies.

Of course, our results do not 'prove' that the behavioral explanations are correct, nor do they refute the risk-based explanation. However, our analysis does show that the excess returns are not simply due to higher beta or more exposure to global factors for value, size and momentum. If the stock selection strategies are more risky, it must be due to other risk factors that have not been identified yet. On the other hand, the evidence for emerging markets is consistent with behavioral explanations, although we would not qualify our findings as a complete proof. Our conclusion for the time being is that the circumstantial evidence points towards behavioral explanations, but more research is needed to reach a final verdict.

Such further research could involve using a broader set of risk indicators to test whether the strategies lead to portfolios bearing more risk in dimensions not measured by the value, size and momentum factors. A specific possibility would be to account for macroeconomic risk explicitly, see Chordia and Shivakumar (2002) and Griffin, Ji and Martin (2003). At the same time, a broader set of indicators that would correlate with investor sentiment could be tested to provide further evidence for behavioral explanations. Another source of data that could provide interesting indicators of sentiment concerns company policies. Overoptimism of investors might be interrelated with overoptimism of management, which could be tested by looking for example at investment policy of the company and subsequent return on these investments. 


\section{References}

Abarbanell, J.S., and V.L. Bernard, 1992, Tests of analysts' overreaction/underreaction to earnings information as an explanation for anomalous stock-price behavior, Journal of Finance 47, 1181-1207.

Achour, D., C.R. Harvey, G. Hopkins, and C. Lang, 1998, Stock selection in emerging markets: portfolio strategies for Malaysia, Mexico and South Africa, Emerging Markets Quarterly 2 (Winter), 38-91.

Achour, D., C.R. Harvey, G. Hopkins, and C. Lang, 1999a, Stock selection in Malaysia, Emerging Markets Quarterly 3 (Spring), 54-91.

Achour, D., C.R. Harvey, G. Hopkins, and C. Lang, 1999b, Stock selection in Mexico, Emerging Markets Quarterly 3 (Fall), 1-38.

Achour, D., C.R. Harvey, G. Hopkins, and C. Lang, 1999c, Firm Characteristics and Investment Strategies in Africa: the Case of South Africa, African Finance Journal $1,1-39$.

Alexander, G.J., 2000, On back-testing 'zero-investment' strategies, Journal of Business 73, 255-278.

Ang, A., J. Chen and Y. Xing, 2004, Downside risk, Columbia University, working paper.

Barberis, N., A. Shleifer, and R.W. Vishny, 1998, A model of investor sentiment, Journal of Financial Economics 49, 307-343.

Barry, C.B., E. Goldreyer, L. Lockwood and M. Rodriguez, 2002, Robustness of size and value effects in emerging markets, 1985-2000, Emerging Markets Review 3, 1-30.

Bekaert, G., and C.R. Harvey, 1995, Time-varying world market integration, Journal of Finance 50, 403-444.

Bekaert, G., and C.R. Harvey, 1997, Emerging equity market volatility, Journal of Financial Economics 43, 29-77.

Bekaert, G., and C.R. Harvey, 2000a, Capital flows and the behavior of emerging market equity returns, in S. Edwards (ed.), Capital Flows and the Emerging Economies: Theory, Evidence and Controversies, Chicago: University of Chicago Press, pp. 159-194.

Bekaert, G., and C.R. Harvey, 2000b, Foreign speculators and emerging equity markets, Journal of Finance 55, 565-614.

Bekaert, G., and C.R. Harvey, 2002, Research in emerging market finance: looking to the future, Emerging Markets Review 3, 429-448.

Bekaert, G., and C.R. Harvey, 2003, Emerging markets finance, Journal of Empirical Finance 10, 3-55.

Bekaert, G., and M.S. Urias, 1996, Diversification, integration, and emerging market closed-end funds, Journal of Finance 51, 835-870.

Carhart, M.M., 1997, On persistence in mutual fund performance, Journal of Finance 52, $57-82$.

Chan, L.K.C., N. Jegadeesh, and J. Lakonishok, 1996, Momentum strategies, Journal of Finance 51, 1681-1713.

Chordia, T. and L. Shivakumar, 2002, Momentum, business cycle, and time-varying expected returns, Journal of Finance 57, 985-1019. 
Claessens, S., S. Dasgupta, and J. Glen, 1998, The cross section of stock returns: Evidence from emerging markets, Emerging Markets Quarterly 2, 4-13.

Cooper, M.J., R.C. Gutierrez and A. Hameed, 2004, Market states and momentum, Journal of Finance 59, 1345-1365.

Daniel, K., D. Hirshleifer, and A. Subrahmanyam, 1998, Investor psychology and security market under- and overreactions, Journal of Finance 53, 1839-1885.

De Roon, F.A., Th.E. Nijman, and B.J.M. Werker, 2001, Testing for mean-variance spanning with short sales constraints and transaction costs: the case of emerging markets, Journal of Finance 56, 721-742.

Doukas, J.A., C. Kim and C. Pantzalis, 2002, A test of the errors-in-expectations explanation of the value/glamour stock returns performance: Evidence from analysts' forecasts, Journal of Finance 57, 2143-2165.

Easterwood, J.C. and S.R. Nutt, 1999, Inefficiency in analysts' earnings forecasts: systematic misreaction or systematic optimism?, Journal of Finance 54, 1777-1797.

Edison, H.J. and F.E. Warnock, 2003, A simple measure of the intensity of capital controls, Journal of Empirical Finance 10, 81-103.

Estrada, J., 2000, The cost of equity in emerging markets: A downside approach, Emerging Markets Quarterly 4 (Fall), 19-30.

Estrada, J., 2001, The cost of equity in emerging markets: A downside approach (II), Emerging Markets Quarterly 4 (Spring), 63-72.

Fama, E.F., and K.R. French, 1993, Common risk factors in the returns on stocks and bonds, Journal of Financial Economics 33, 3-56.

Fama, E.F., and K.R. French, 1996, Multifactor explanations of asset pricing anomalies, Journal of Finance 51, 55-84.

Fama, E.F., and K.R. French, 1998, Value versus growth: the international evidence, Journal of Finance 53, 1975-1999.

Ferson, W.E. and C.R. Harvey, 1999, Conditioning variables and the cross section of stock returns, Journal of Finance 54, 1325-1360.

Griffin, J.M., X. Ji and J.S. Martin, 2003, Momentum investing and business cycle risk: evidence from pole to pole, Journal of Finance 58, 2515-2547.

Harvey, C.R., 1995, Predictable risk and return in emerging markets, Review of Financial Studies 8, 773-816.

Hong, H. and J.D. Kubik, 2003, Analyzing the analysts: career concerns and biased earnings forecasts, Journal of Finance 58, 313-351.

Hong, H., and J.C. Stein, 1999, A unified theory of underreaction, momentum trading, and overreaction in asset markets, Journal of Finance 54, 2143-2184.

Hong, H., T.Lim, and J.C. Stein, 2000, Bad news travels slowly: size, analyst coverage, and the profitability of momentum strategies, Journal of Finance 55, 265-295.

Jegadeesh, N., and S. Titman, 1993, Returns to buying winners and selling losers: implications for stock market efficiency, Journal of Finance 48, 65-91.

Jegadeesh, N., and S. Titman, 2001, Profitability of momentum strategies: an evaluation of alternative explanations, Journal of Finance 56, 699-720.

Lakonishok, J., A. Shleifer, and R.W. Vishny, 1994, Contrarian investment, extrapolation and risk, Journal of Finance 49, 1541-1578. 
Lee, C.M.C., and B. Swaminathan, 2000, Price momentum and trading volume, Journal of Finance 55, 2017-2069.

Lim, T., 2001, Rationality and analysts' forecast bias, Journal of Finance 56, 369-385.

Nagel, S., 2002, Is momentum caused by delayed overreaction?, working paper, London Business School.

Patel, S.A., 1998, Cross-sectional variation in emerging markets equity returns, January 1988-March 1997, Emerging Markets Quarterly 2, 57-70.

Rouwenhorst, K.G., 1998, International momentum strategies, Journal of Finance 53, $267-284$.

Rouwenhorst, K.G., 1999, Local return factors and turnover in emerging stock markets, Journal of Finance 54, 1439-1464.

van der Hart, J., E. Slagter and D. van Dijk, 2003, Stock selection strategies in emerging markets, Journal of Empirical Finance 10, 105-132. 
Table 1: Returns of Univariate Stock Selection Strategies

\begin{tabular}{lcccccccc}
\hline \hline Factor & \# Stocks & Top & EWI & Bottom & TMI & $t$ (TMI) & TMB & $t$ (TMB) \\
\hline B/M & 576 & 1.46 & 0.93 & 0.74 & 0.53 & 3.76 & 0.73 & 3.39 \\
E/P & 576 & 1.26 & 0.93 & 0.58 & 0.32 & 3.04 & 0.68 & 3.76 \\
6MR & 576 & 1.30 & 0.93 & 0.58 & 0.36 & 3.51 & 0.74 & 3.75 \\
ER FY1 & 489 & 1.03 & 0.79 & 0.45 & 0.24 & 3.13 & 0.59 & 4.80 \\
\hline
\end{tabular}

Note: At the beginning of each month between December 1988 and June 2004, all stocks for which the necessary information is available are ranked by country in descending order according to the value of the factor indicated in the first column. $\mathrm{B} / \mathrm{M}$ is the book-to-market ratio; $\mathrm{E} / \mathrm{P}$ is the earnings-to-price ratio; $6 \mathrm{MR}$ is the average return over the previous six months; ER FY1 is the past three-month average earnings revisions for the current fiscal year. For each country equally weighted portfolios are formed from the top and bottom 15 percent of stocks, which are combined into equally weighted internationally diversified portfolios (Top and Bottom). EWI is the equally weighted index of all stocks in the sample. Positions are held for six months and are not rebalanced. Monthly, non-overlapping returns are computed as the average return on the six similar portfolios which are held during each month. Column 2 reports the average number of stocks in the different samples. Columns 3-5 report the average returns of the Top, EWI and Bottom portfolios, expressed as percentage per month. Columns 6-7 and 8-9 report the average excess returns and the corresponding $t$-statistics of the Top Minus EWI (TMI) portfolio and the Top Minus Bottom (TMB) portfolio, respectively.

Table 2: Subsample Returns of Univariate Stock Selection Strategies

\begin{tabular}{lcccccccc}
\hline \hline \multirow{2}{*}{ Factor } & \multicolumn{2}{c}{$1989.7-1994.6$} & & \multicolumn{2}{c}{$1994.7-1999.6$} & & \multicolumn{2}{c}{$1999.7-2004.6$} \\
\cline { 2 - 3 } & TMI & $t($ TMI $)$ & & TMI & $t($ TMI $)$ & & TMI & $t($ TMI $)$ \\
\hline B/M & 0.84 & 2.66 & & 0.36 & 1.71 & & 0.43 & 2.59 \\
EM & 0.44 & 1.81 & & 0.33 & 2.10 & & 0.44 & 3.82 \\
EMR & 0.26 & 1.43 & & 0.38 & 2.28 & & 0.43 & 2.16 \\
ER FY1 & 0.30 & 2.12 & & 0.27 & 2.78 & & 0.29 & 2.73 \\
\hline
\end{tabular}

Note: The table reports the average excess returns, expressed as percentage per month, and the corresponding t-statistics of the Top Minus EWI (TMI) portfolio over the indicated five-year subsample periods. See Table 1 for further details on the portfolio construction methodology. 
Table 3: Emerging Market Risk of Top and Bottom Portfolios in Stock Selection Strategies

\begin{tabular}{llrrccc}
\hline \hline Strategy & Portfolio & \multicolumn{1}{c}{$\alpha$} & \multicolumn{1}{c}{$t(\alpha)$} & $\beta_{\mathrm{EM}}$ & $t\left(\beta_{\mathrm{EM}}-1\right)$ & $\bar{R}^{2}$ \\
\hline \multirow{2}{*}{ B/M } & Top & 0.53 & 3.64 & 1.07 & 3.05 & 0.92 \\
& Bottom & -0.17 & -1.52 & 0.96 & -2.36 & 0.94 \\
\multirow{2}{*}{ E/P } & Top & 0.34 & 3.04 & 1.00 & 0.12 & 0.95 \\
& Bottom & -0.35 & -3.22 & 1.07 & 4.02 & 0.95 \\
\multirow{2}{*}{$6 \mathrm{MR}$} & Top & 0.38 & 3.49 & 1.00 & 0.20 & 0.95 \\
& Bottom & -0.36 & -3.15 & 1.06 & 3.22 & 0.95 \\
\multirow{2}{*}{ ER FY1 } & Top & 0.25 & 3.16 & 0.98 & -1.82 & 0.97 \\
& Bottom & -0.34 & -3.93 & 1.01 & 0.96 & 0.97 \\
\hline
\end{tabular}

Note: The table presents coefficient estimates and $t$-statistics from the regression

$$
R_{p, t}-R_{f, t}=\alpha+\beta_{\mathrm{EM}}\left(R_{\mathrm{EM}, t}-R_{f, t}\right)+\varepsilon_{t},
$$

where $R_{p, t}$ is the monthly return of the equally weighted top or bottom portfolio, $R_{\mathrm{EM}, t}$ is the EWI benchmark return, and $R_{f, t}$ is the 1-month US T-bill return. $t(\alpha)$ is the $t$-statistic of $\alpha$, and $t\left(\beta_{\mathrm{EM}}-1\right)$ is the $t$-statistic of $\beta_{\mathrm{EM}}$ minus one. The regression $\bar{R}^{2}$ is adjusted for degrees of freedom.

Table 4: Downside and Upside Emerging Market Risk of Top and Bottom Portfolios in Stock Selection Strategies

\begin{tabular}{llrrlrrrrrr}
\hline \hline Strategy & Portfolio & \multicolumn{1}{c}{$\alpha^{-}$} & $t\left(\alpha^{-}\right)$ & $\beta_{\mathrm{EM}}^{-}$ & $t\left(\beta_{\mathrm{EM}}^{-}-1\right)$ & $\alpha^{+}$ & $t\left(\alpha^{+}\right)$ & $\beta_{\mathrm{EM}}^{+} t\left(\beta_{\mathrm{EM}}^{+}-1\right)$ & $\bar{R}^{2}$ \\
\hline \multirow{2}{*}{ B/M } & Top & -0.05 & -0.15 & 0.99 & -0.25 & 0.65 & 2.28 & 1.07 & 1.48 & 0.93 \\
& Bottom & 0.08 & 0.31 & 1.00 & -0.05 & -0.16 & -0.73 & 0.95 & -1.42 & 0.94 \\
\multirow{2}{*}{$\mathrm{E} / \mathrm{P}$} & Top & 0.18 & 0.68 & 0.98 & -0.55 & 0.36 & 1.65 & 1.00 & 0.08 & 0.95 \\
& Bottom & -0.60 & -2.34 & 1.02 & 0.63 & -0.48 & -2.21 & 1.10 & 2.82 & 0.96 \\
\multirow{2}{*}{$6 \mathrm{MR}$} & Top & 0.53 & 2.06 & 1.02 & 0.62 & 0.32 & 1.54 & 1.01 & 0.21 & 0.95 \\
& Bottom & -0.23 & -0.87 & 1.07 & 1.65 & -0.52 & -2.34 & 1.08 & 2.24 & 0.95 \\
\multirow{2}{*}{ ER FY1 } & Top & 0.23 & 1.31 & 0.98 & -0.68 & 0.40 & 2.47 & 0.95 & -1.81 & 0.97 \\
& Bottom & -0.34 & -1.76 & 1.01 & 0.22 & -0.47 & -2.60 & 1.04 & 1.21 & 0.97 \\
\hline
\end{tabular}

Note: The table presents coefficient estimates and $t$-statistics from the regression

$$
\begin{aligned}
R_{p, t}-R_{f, t}=\alpha^{-} I_{\left\{R_{\mathrm{EM}, t}-R_{f, t}<0\right\}} & +\beta_{\mathrm{EM}}^{-}\left(R_{\mathrm{EM}, t}-R_{f, t}\right) I_{\left\{R_{\mathrm{EM}, t}-R_{f, t}<0\right\}}+ \\
& \alpha^{+} I_{\left\{R_{\mathrm{EM}, t}-R_{f, t} \geq 0\right\}}+\beta_{\mathrm{EM}}^{+}\left(R_{\mathrm{EM}, t}-R_{f, t}\right) I_{\left\{R_{\mathrm{EM}, t}-R_{f, t} \geq 0\right\}}+\varepsilon_{t},
\end{aligned}
$$

where $R_{p, t}$ is the monthly return of the equally weighted top or bottom portfolio, $R_{\mathrm{EM}, t}$ is the EWI benchmark return, $R_{f, t}$ is the 1-month US T-bill return, and $I_{\{A\}}$ is the indicator function for the event $A$. $t(\alpha)$ is the $t$-statistic of $\alpha$, and $t\left(\beta_{\mathrm{EM}}-1\right)$ is the $t$-statistic of $\beta_{\mathrm{EM}}$ minus one. The regression $\bar{R}^{2}$ is adjusted for degrees of freedom. 
Table 5: Four-Factor Regressions for Top and Bottom Portfolios in Stock Selection Strategies Using Global Factor Portfolios

\begin{tabular}{lllllllllllll}
\hline \hline Portfolio & & $\alpha$ & $t(\alpha)$ & $\beta_{\mathrm{M}}$ & $t\left(\beta_{\mathrm{M}}[-1]\right)$ & $\beta_{\mathrm{HML}}$ & $t\left(\beta_{\mathrm{HML}}\right)$ & $\beta_{\mathrm{SMB}}$ & $t\left(\beta_{\mathrm{SMB}}\right)$ & $\beta_{\mathrm{UMD}}$ & $t\left(\beta_{\mathrm{UMD}}\right)$ & $\bar{R}^{2}$ \\
\hline B/M & Top & 0.89 & 1.99 & 0.89 & -0.97 & 0.19 & 1.22 & 0.49 & 3.83 & -0.13 & -1.48 & 0.36 \\
& EWI & 0.33 & 0.85 & 0.85 & -1.50 & 0.13 & 0.99 & 0.42 & 3.82 & -0.11 & -1.37 & 0.40 \\
& Bottom & 0.11 & 0.29 & 0.86 & -1.46 & 0.05 & 0.37 & 0.36 & 3.35 & -0.06 & -0.73 & 0.41 \\
& TMI & 0.54 & 3.53 & 0.03 & 0.77 & 0.06 & 1.06 & 0.06 & 1.51 & -0.03 & -0.85 & -0.00 \\
& TMB & 0.78 & 3.39 & 0.02 & 0.34 & 0.14 & 1.82 & 0.13 & 1.96 & -0.07 & -1.59 & 0.02 \\
E/P & Top & 0.64 & 1.55 & 0.86 & -1.29 & 0.18 & 1.27 & 0.45 & 3.87 & -0.10 & -1.22 & 0.38 \\
& EWI & 0.33 & 0.85 & 0.85 & -1.50 & 0.13 & 0.99 & 0.42 & 3.82 & -0.11 & -1.37 & 0.40 \\
& Bottom & 0.03 & 0.06 & 0.91 & -0.78 & 0.11 & 0.77 & 0.42 & 3.49 & -0.14 & -1.63 & 0.39 \\
& TMI & 0.31 & 2.66 & 0.01 & 0.25 & 0.05 & 1.15 & 0.02 & 0.73 & 0.01 & 0.31 & -0.01 \\
& TMB & 0.68 & 3.58 & -0.07 & -1.35 & 0.07 & 1.01 & 0.02 & 0.45 & 0.04 & 1.03 & 0.02 \\
$6 \mathrm{MR}$ & Top & 0.55 & 1.34 & 0.89 & -1.04 & 0.18 & 1.28 & 0.44 & 3.82 & 0.01 & 0.14 & 0.37 \\
& EWI & 0.33 & 0.85 & 0.85 & -1.50 & 0.13 & 0.99 & 0.42 & 3.82 & -0.11 & -1.37 & 0.40 \\
& Bottom & 0.14 & 0.34 & 0.88 & -1.10 & 0.09 & 0.63 & 0.42 & 3.62 & -0.23 & -2.82 & 0.42 \\
& TMI & 0.22 & 2.13 & 0.04 & 1.47 & 0.05 & 1.30 & 0.02 & 0.64 & 0.11 & 5.58 & 0.13 \\
& TMB & 0.50 & 2.63 & 0.01 & 0.10 & 0.09 & 1.38 & 0.01 & 0.26 & 0.24 & 6.28 & 0.18 \\
ER FY1 & Top & 0.33 & 0.84 & 0.91 & -0.92 & 0.22 & 1.58 & 0.39 & 3.49 & -0.08 & -0.98 & 0.39 \\
& EWI & 0.13 & 0.32 & 0.90 & -0.99 & 0.21 & 1.51 & 0.40 & 3.53 & -0.09 & -1.20 & 0.39 \\
& Bottom & -0.19 & -0.47 & 0.92 & -0.75 & 0.16 & 1.13 & 0.40 & 3.46 & -0.09 & -1.16 & 0.40 \\
& TMI & 0.22 & 2.68 & 0.01 & 0.25 & 0.01 & 0.21 & -0.01 & -0.51 & 0.02 & 1.08 & -0.01 \\
& TMB & 0.58 & 4.41 & -0.02 & -0.67 & 0.05 & 1.16 & -0.01 & -0.36 & 0.02 & 0.67 & 0.01 \\
\hline
\end{tabular}

Note: The table presents coefficient estimates and $t$-statistics from the four-factor model

$$
R_{p, t}-R_{f, t}=\alpha+\beta_{\mathrm{M}}\left(R_{\mathrm{M}, t}-R_{f, t}\right)+\beta_{\mathrm{HML}} R_{\mathrm{HML}, t}+\beta_{\mathrm{SMB}} R_{\mathrm{SMB}, t}+\beta_{\mathrm{UMD}} R_{\mathrm{UMD}, t}+\varepsilon_{t},
$$

where $R_{f, t}$ is the 1-month US T-bill return, $R_{\mathrm{M}, t}$ is the US market return, and $R_{\mathrm{HML}, t}$ (High-Minus-Low), $R_{\mathrm{SMB}, t}$ (Small-Minus-Big), and $R_{\mathrm{UMD}, t}$ Up-Minus-Down) are returns on US book-to-market, size and momentum factor portfolios. $R_{p, t}$ is the return on the top or bottom portfolio of a particular strategy, the corresponding sample of emerging market stocks (EWI), or the excess return on the top portfolio relative to the equally weighted index (TMI) or bottom portfolio (TMB). The risk-free interest rate is not included on the left-hand side in regressions involving the TMI and TMB excess returns. $t($.$) is the t$-statistic for the regression coefficients. $t\left(\beta_{\mathrm{M}}[-1]\right)$ is the $t$-statistic of $\beta_{\mathrm{M}}$ minus one for the regressions with $R_{p, t}$ being the return on the top or bottom portfolio or the equally weighted index; $t\left(\beta_{\mathrm{M}}[-1]\right)$ is the $t$-statistic of $\beta_{\mathrm{M}}$ for the regressions involving the TMI and TMB excess returns. The regression $\bar{R}^{2}$ is adjusted for degrees of freedom. 


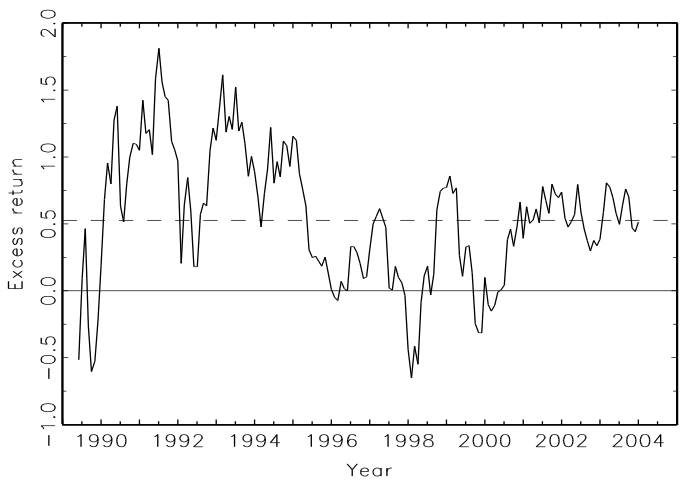

(a) B/M strategy

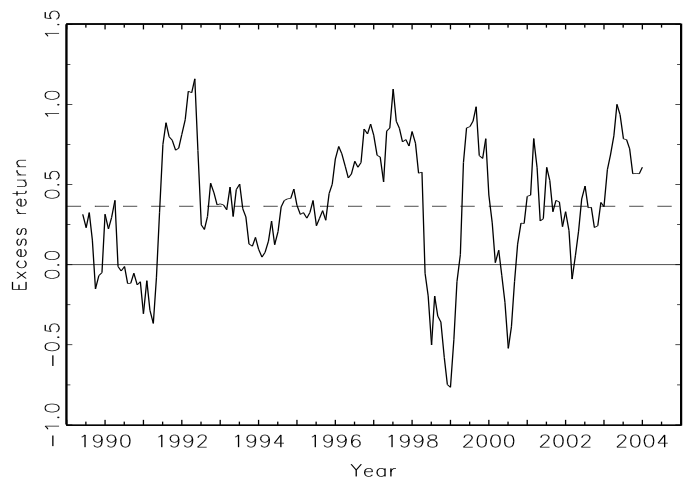

(c) $6 \mathrm{MR}$ strategy

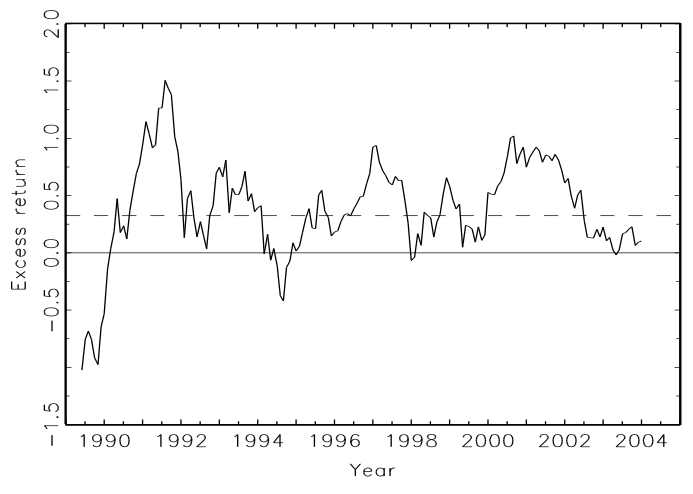

(b) E/P strategy

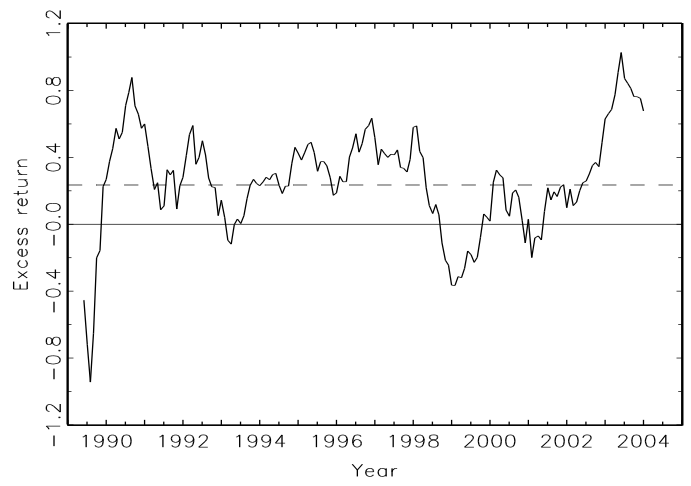

(d) ER FY1 strategy

Figure 1: 12-month moving average of monthly excess returns of the top portfolio relative to the equally weighted index for strategies based on book-to-market $(B / M)$, earnings-to-price (E/P), past 6-month return (6MR), and past three-month earnings revisions for the current fiscal year (ER FY1). The dashed line indicates the mean monthly excess return. 


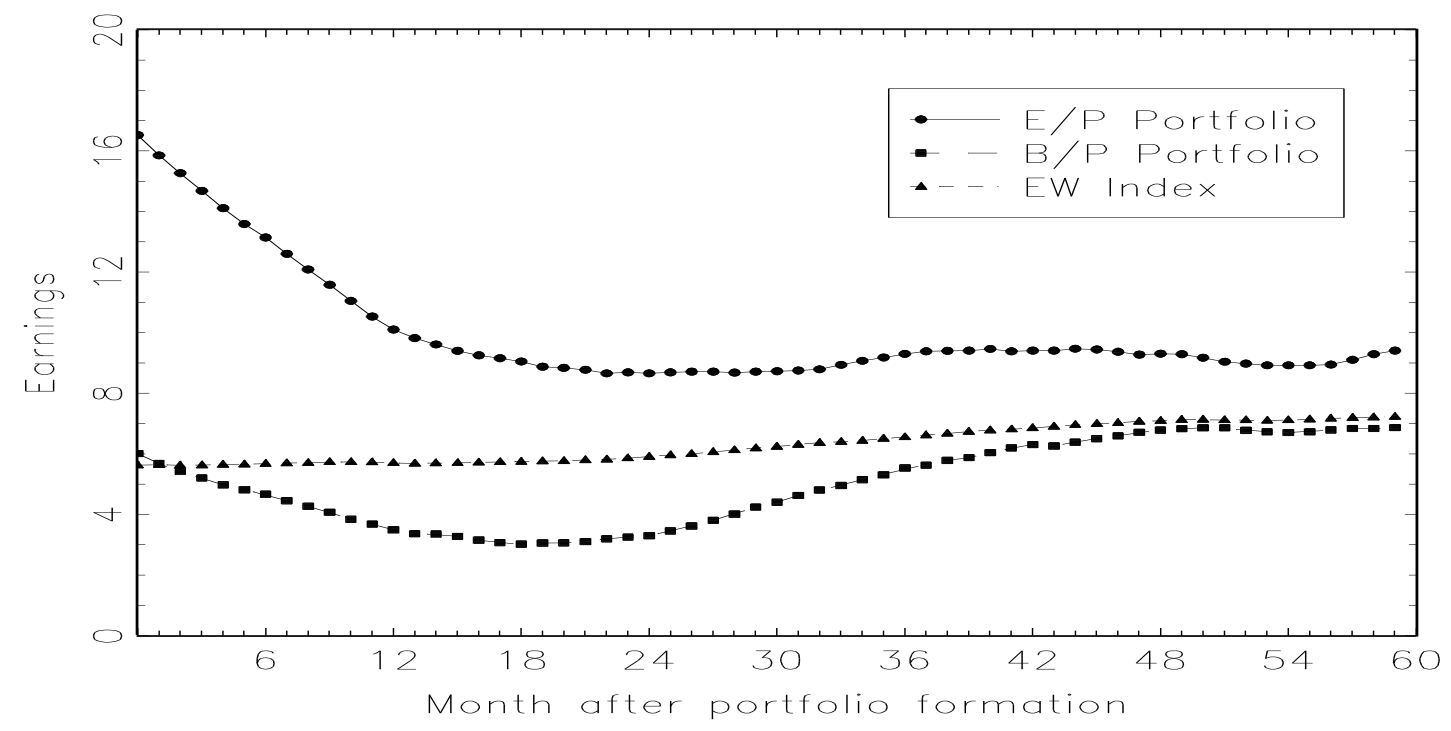

Figure 2: Earnings, expressed as percentage of initial investment, after portfolio formation for the top portfolio of the $\mathrm{B} / \mathrm{M}$ and $\mathrm{E} / \mathrm{P}$ strategies and the equally weighted index of all stocks in the sample. 


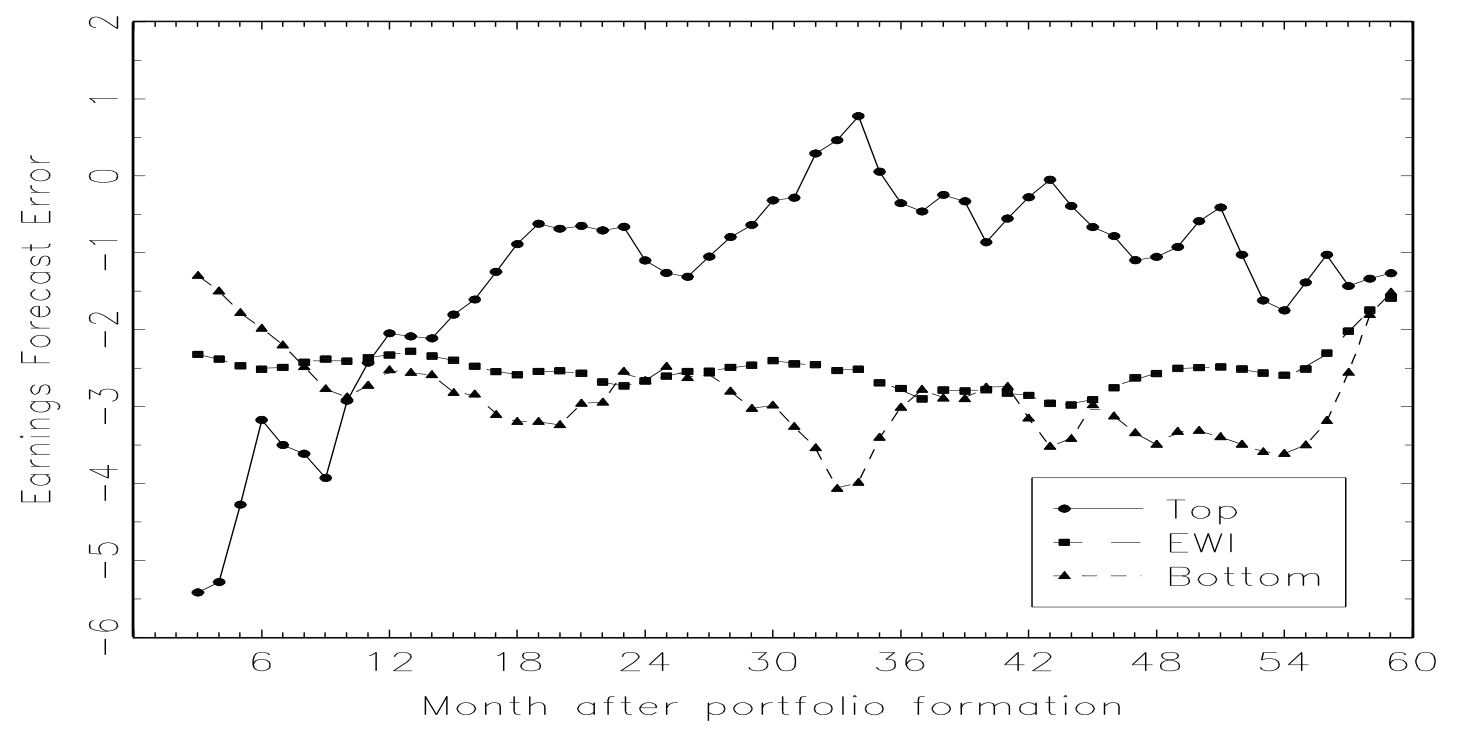

(a) B/M strategy

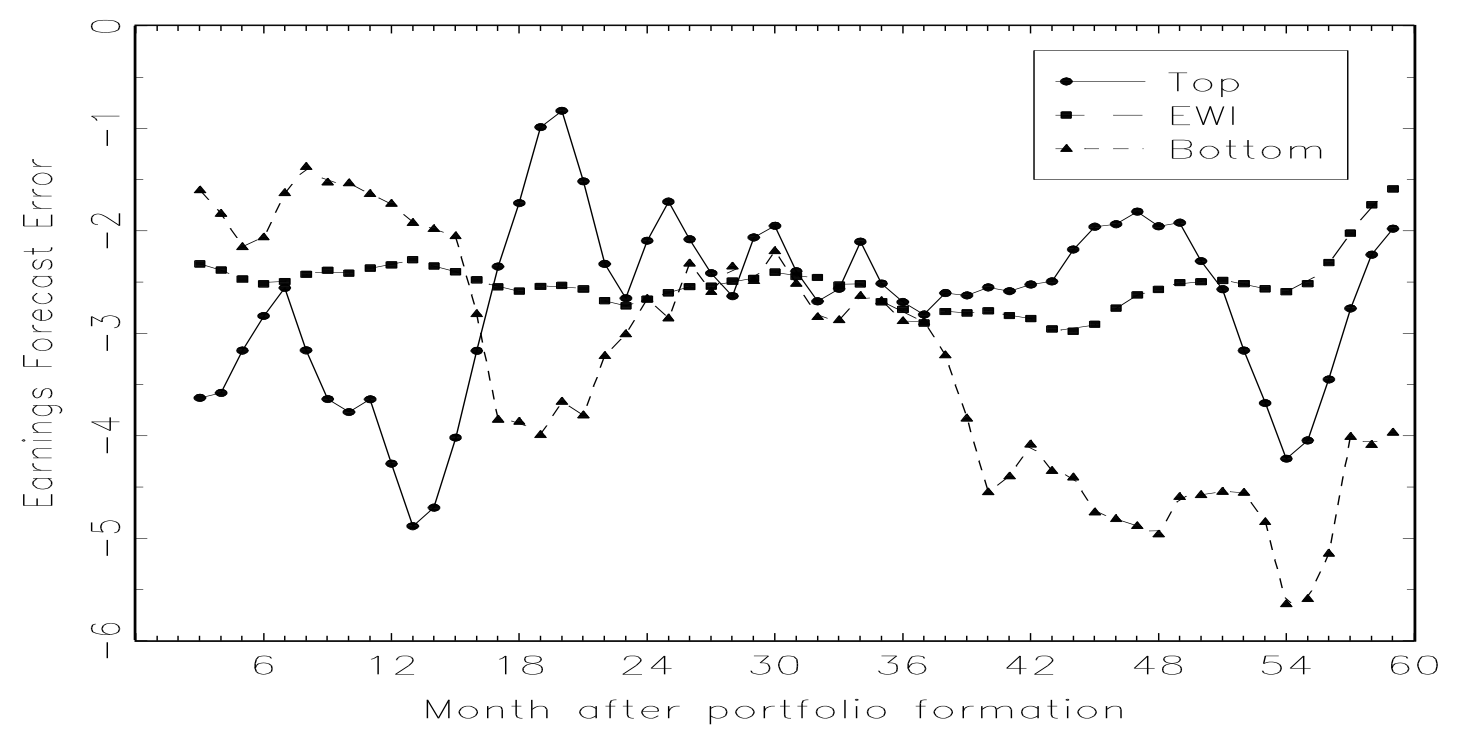

(b) E/P strategy

Figure 3: Three-month moving average of earnings forecast errors after portfolio formation for top and bottom portfolios of the (a) B/M strategy and (b) E/P strategy and for the relevant equally weighted index. 


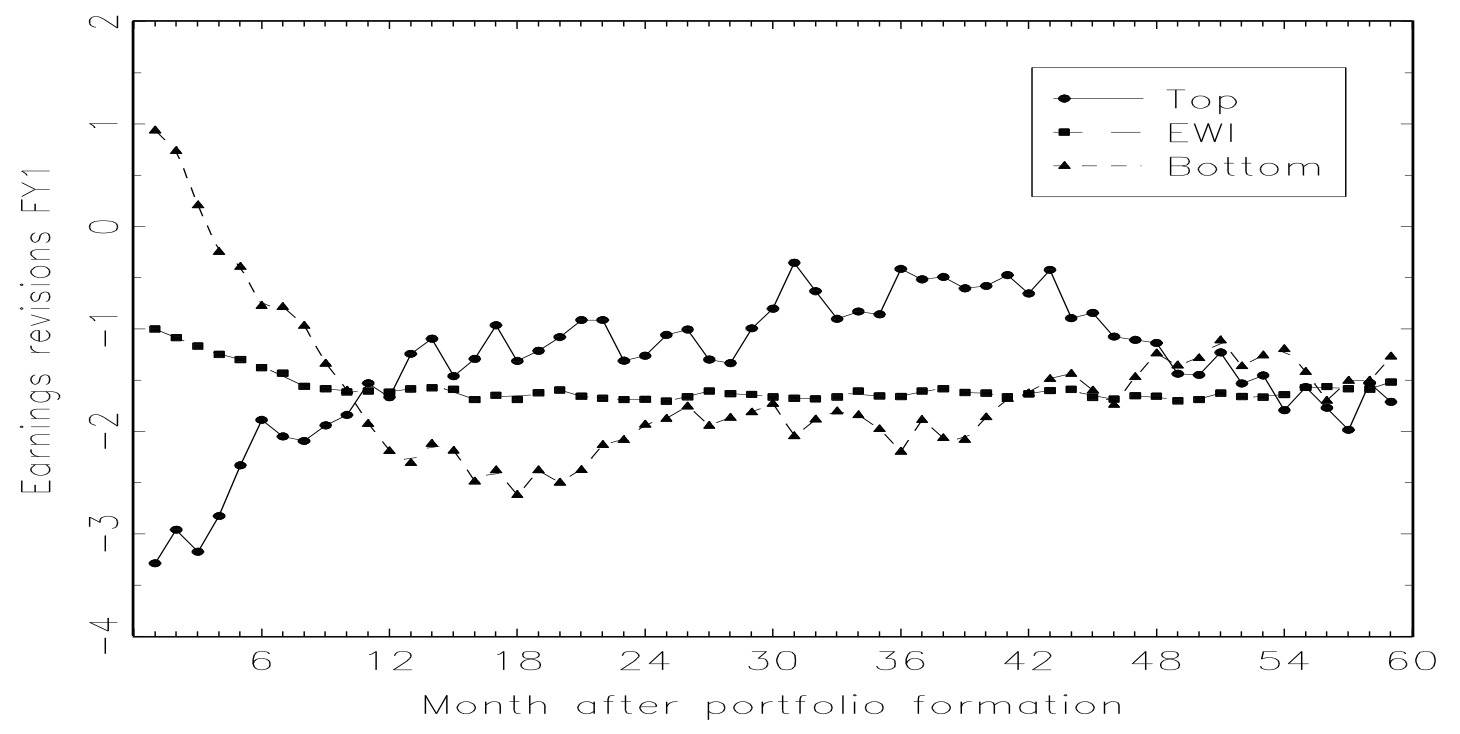

(a) B/M strategy

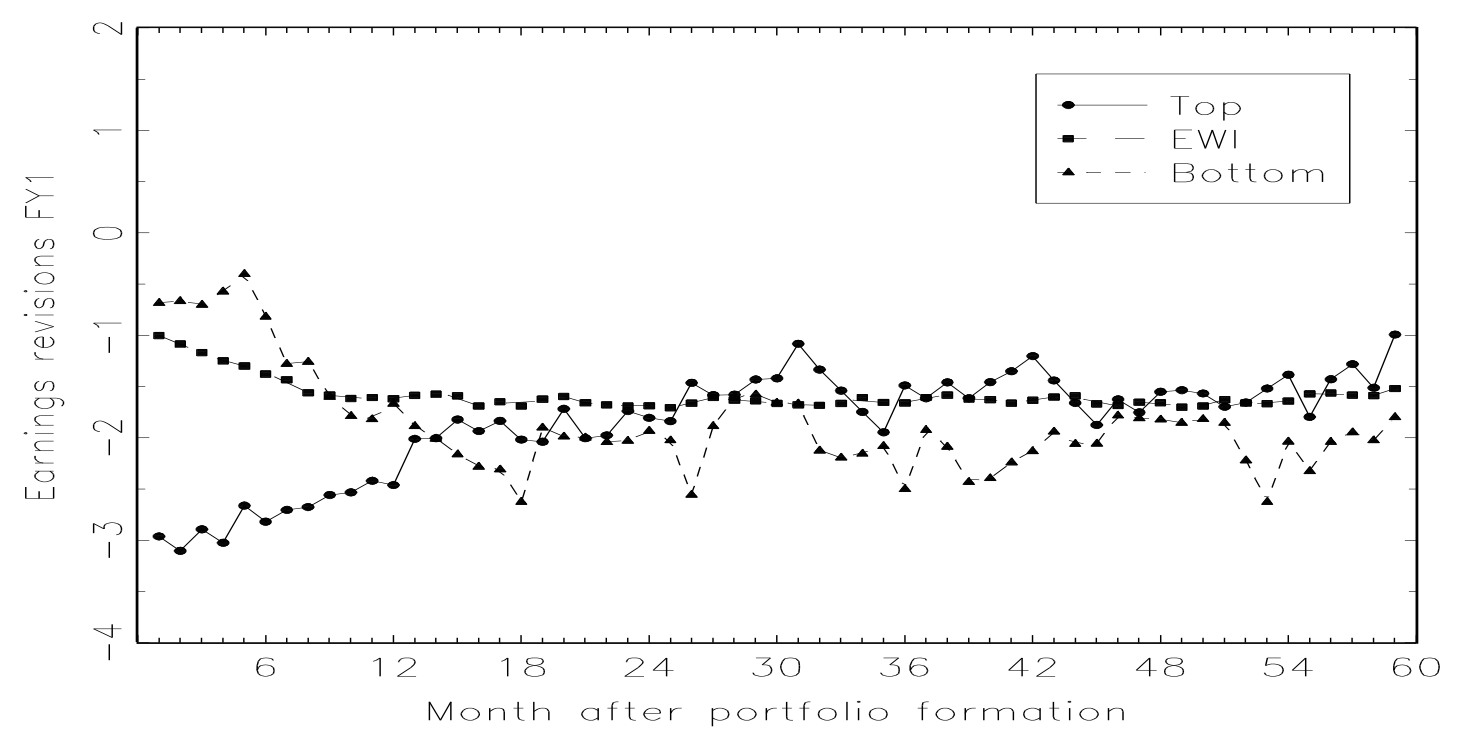

(b) E/P strategy

Figure 4: Monthly earnings revisions after portfolio formation for top and bottom portfolios of the (a) B/M strategy and (b) E/P strategy and for the relevant equally weighted index, expressed as percentage. 


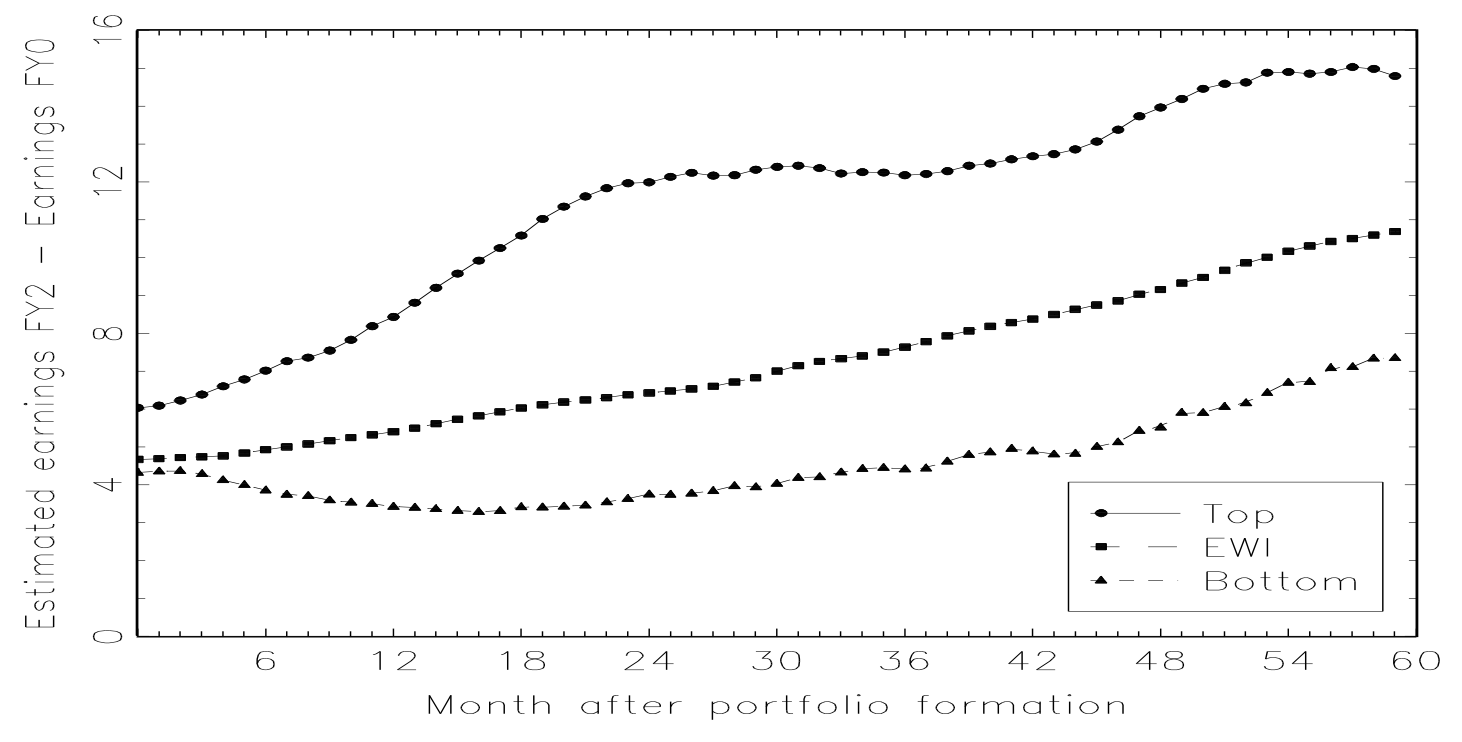

(a) B/M strategy

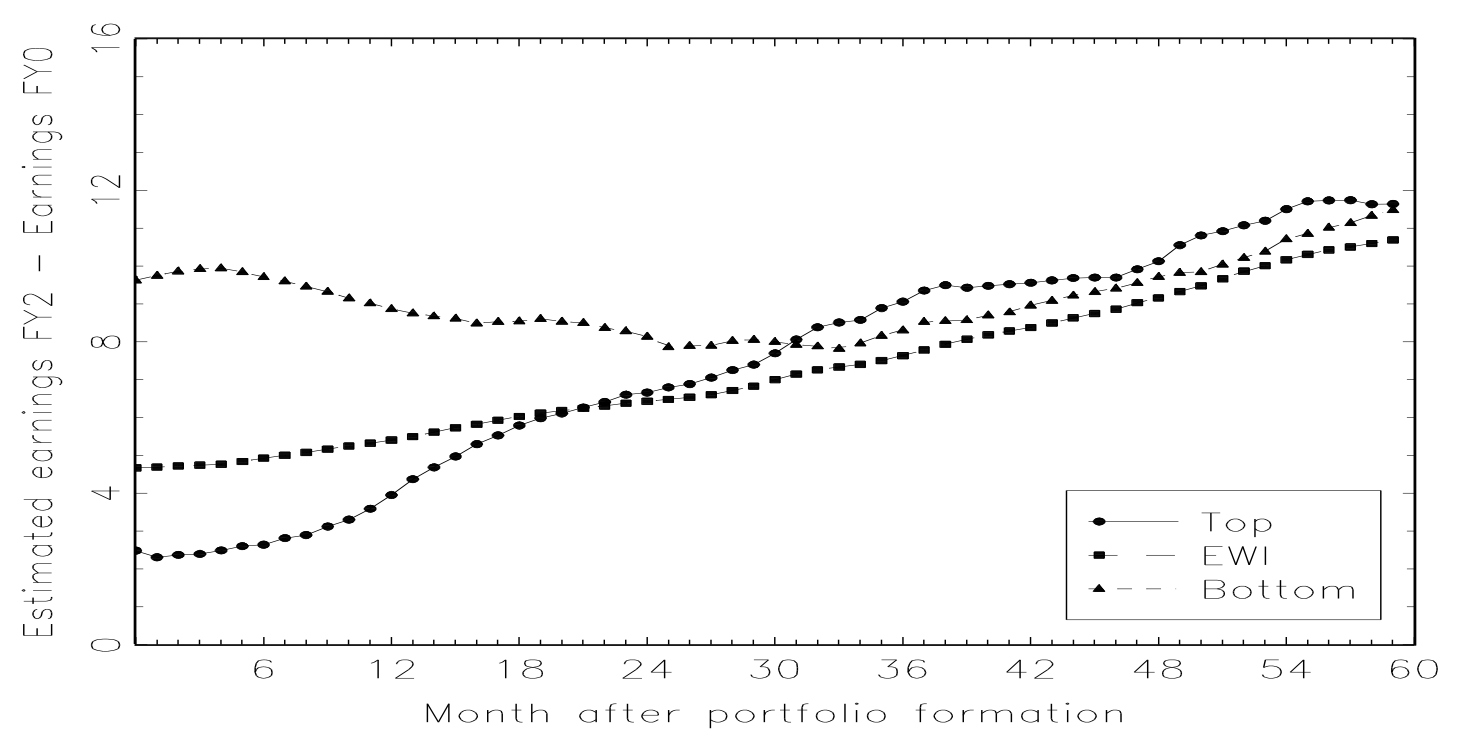

(b) E/P strategy

Figure 5: Difference between estimated earnings for the next fiscal year and the most recent actual earnings for top and bottom portfolios of the (a) B/M strategy and (b) $\mathrm{E} / \mathrm{P}$ strategy and for the relevant equally weighted index, expressed as percentage of initial investment. 


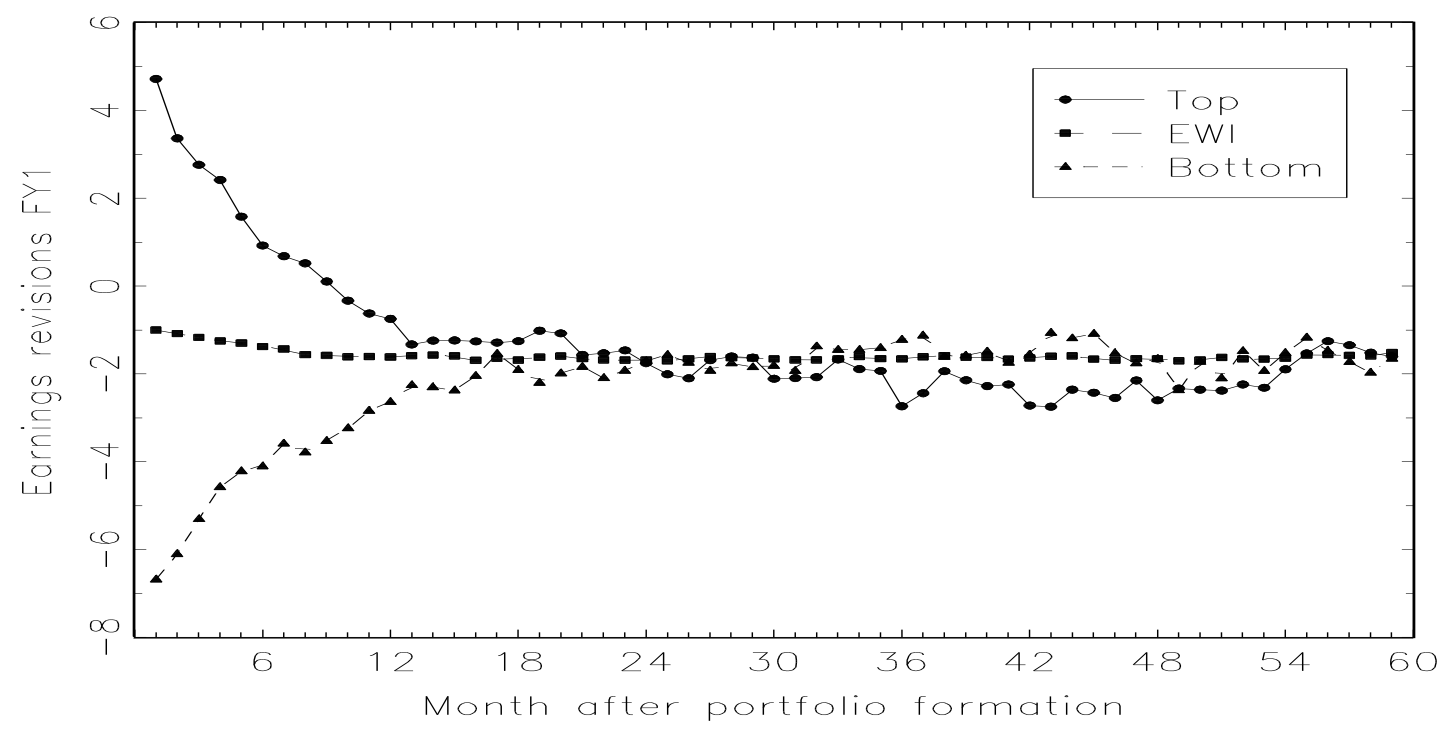

(a) 6MR strategy

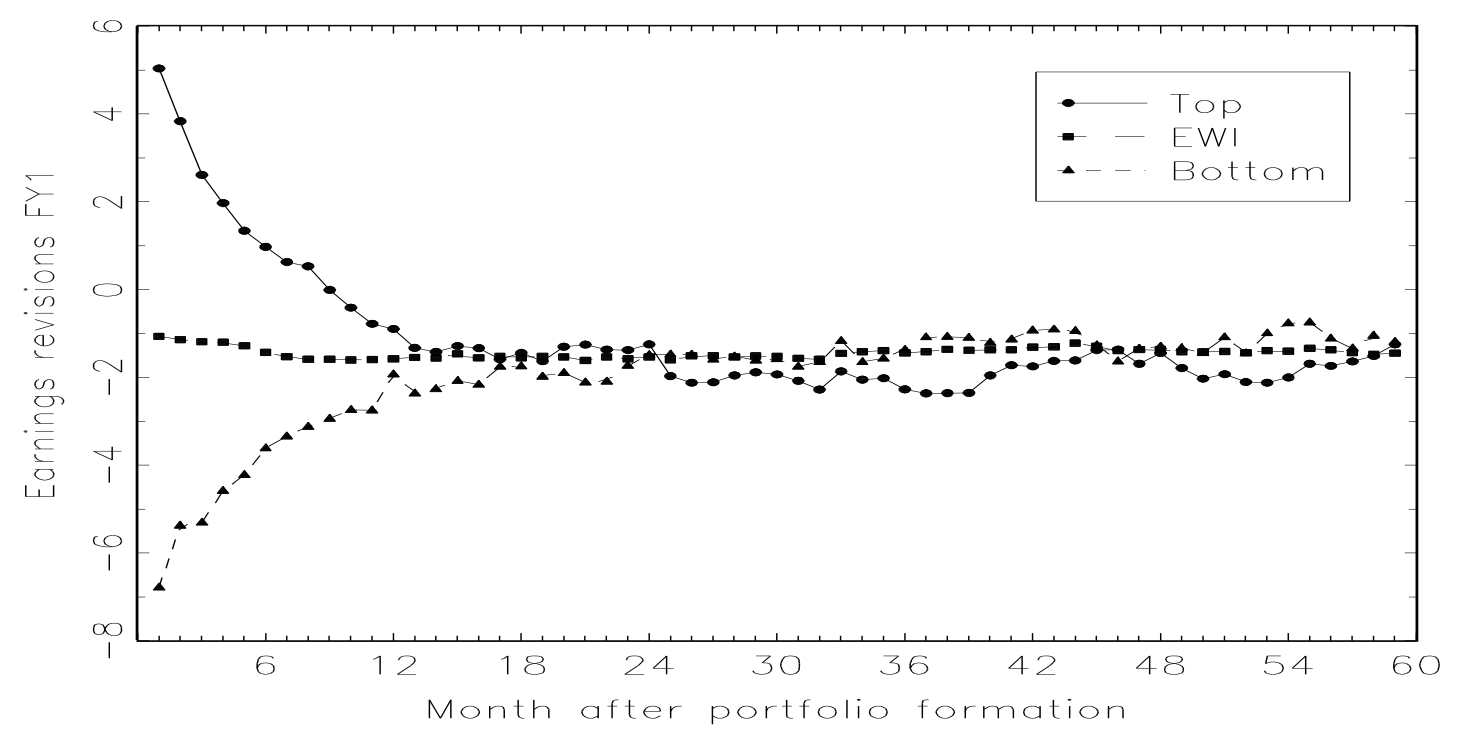

(b) ER FY1 strategy

Figure 6: Monthly earnings revisions after portfolio formation for top and bottom portfolios of the (a) 6MR strategy and (b) ER FY1 strategy and for the relevant equally weighted index, expressed as percentage. 


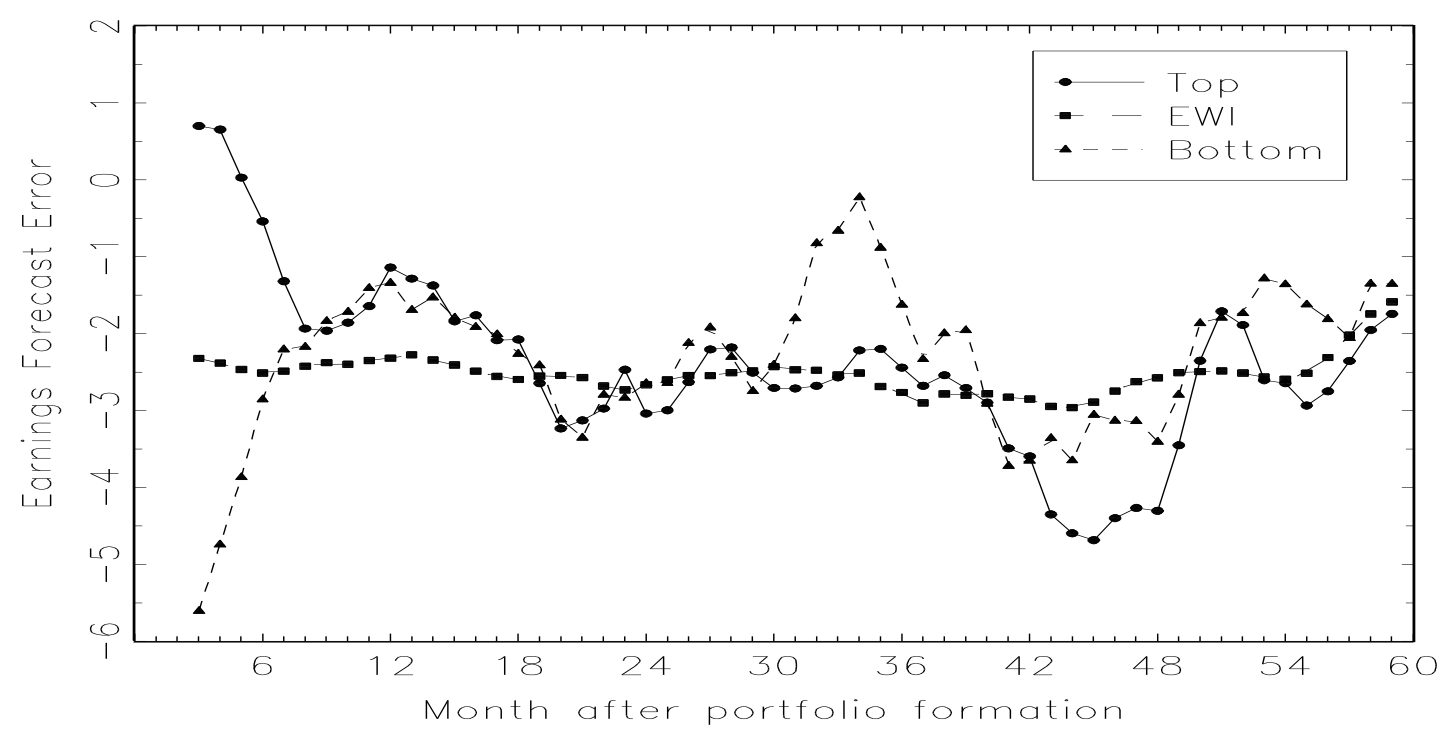

(a) 6MR strategy

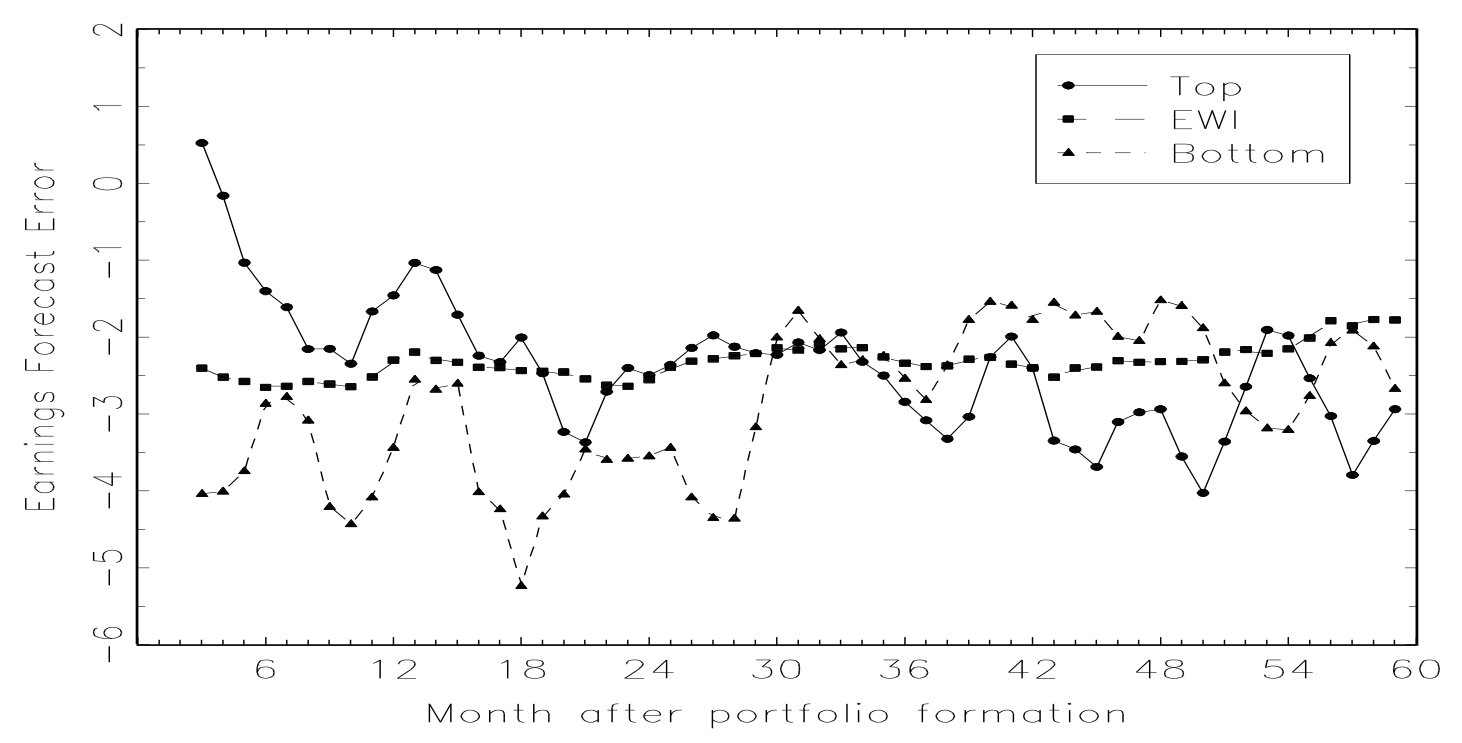

(b) ER FY1 strategy

Figure 7: Three-month moving average of earnings forecast errors after portfolio formation for top and bottom portfolios of the (a) 6MR strategy and (b) ER FY1 strategy and for the relevant equally weighted index. 


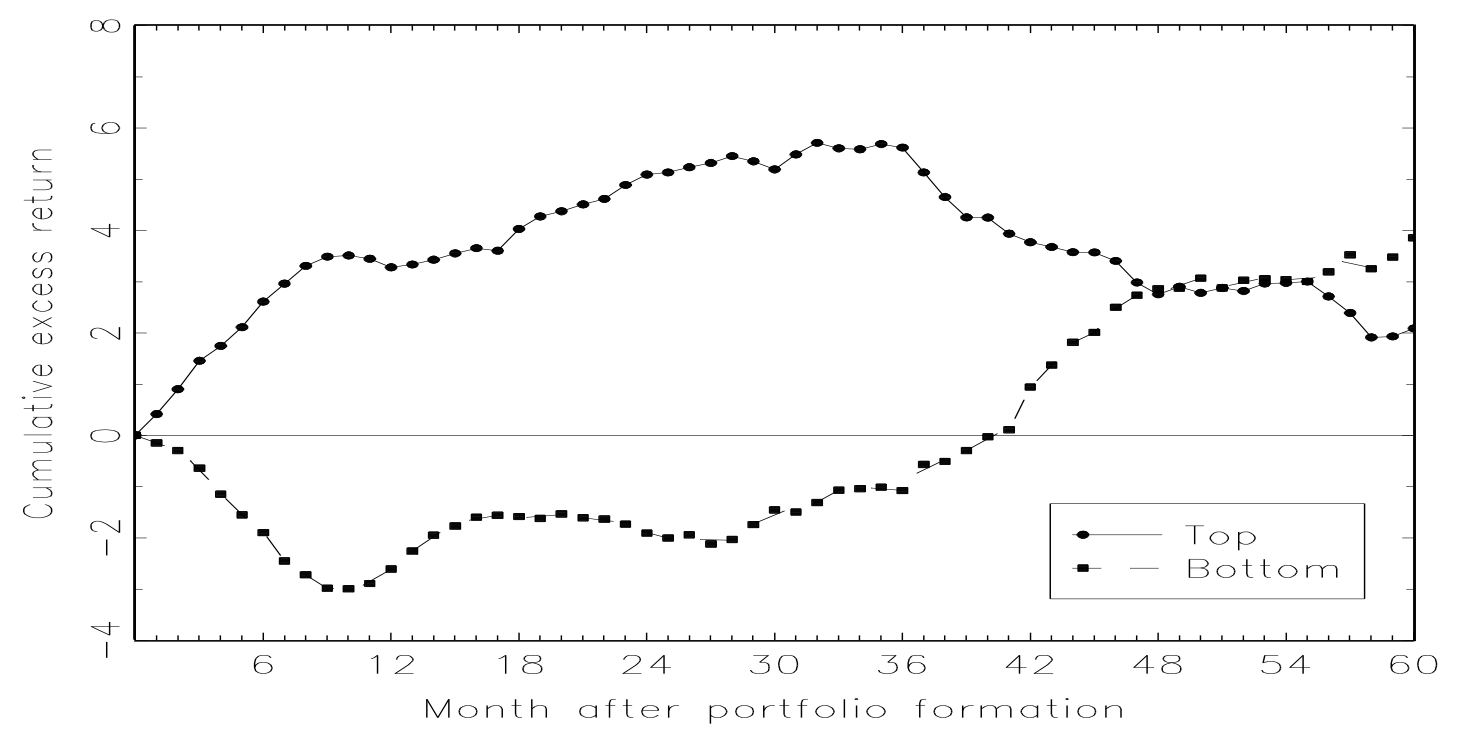

(a) 6MR strategy

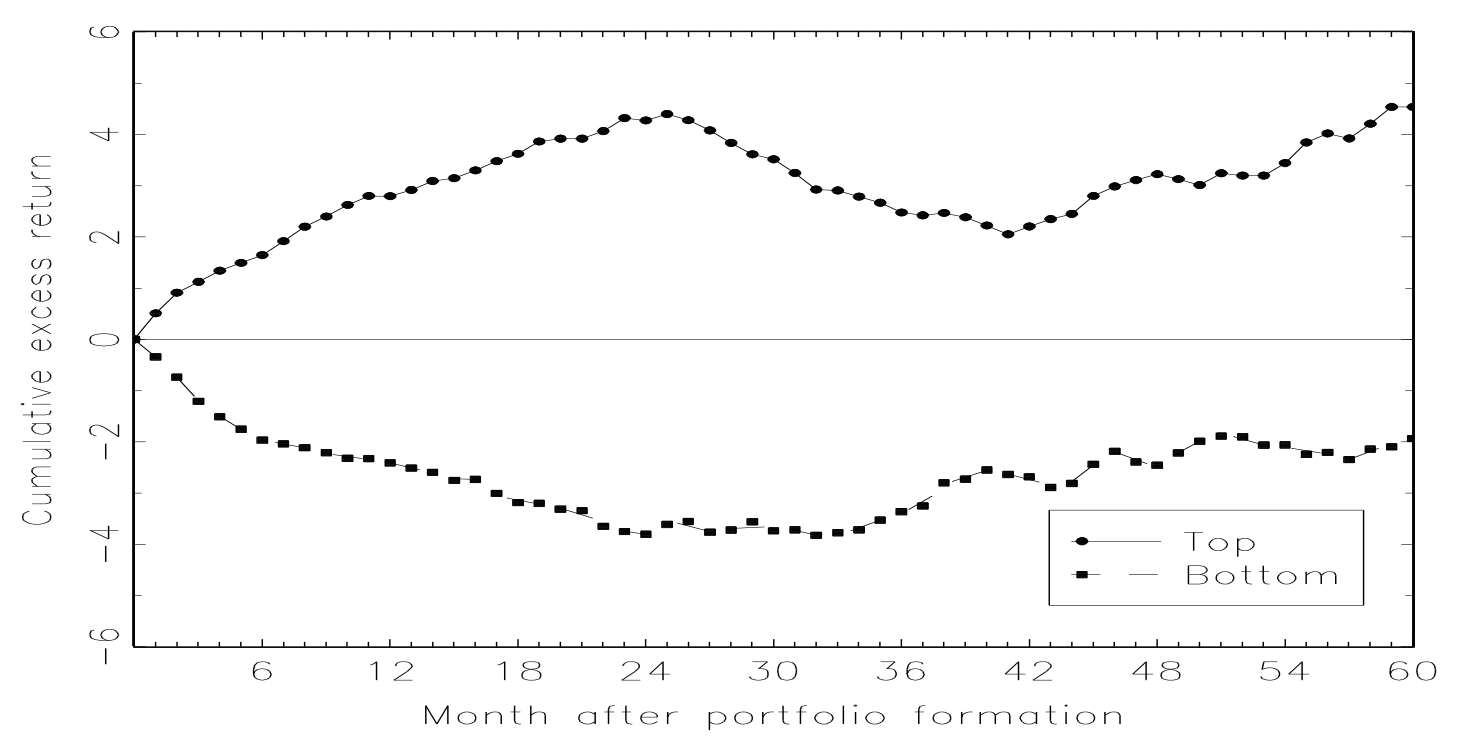

(b) ER FY1 strategy

Figure 8: Cumulative excess returns on top and bottom portfolios of the (a) 6MR strategy and (b) ER FY1 strategy over the relevant equally weighted index during 60 months after portfolio formation. 


\section{Publications in the Report Series Research* in Management}

\section{ERIM Research Program: "Finance and Accounting"}

\section{5}

Royal Ahold: A Failure Of Corporate Governance

Abe De Jong, Douglas V. Dejong, Gerard Mertens en Peter Roosenboom

ERS-2005-002-F\&A

http://hdl.handle.net/1765/1863

Capital Structure Policies in Europe: Survey Evidence

Dirk Brounen, Abe de Jong and Kees Koedijk

ERS-2005-005-F\&A

A Comparison of Single Factor Markov-Functional and Multi Factor Market Models

Raoul Pietersz, Antoon A. J. Pelsser

ERS-2005-008-F\&A

Efficient Rank Reduction of Correlation Matrices

Igor Grubišić and Raoul Pietersz

ERS-2005-009-F\&A

Generic Market Models

Raoul Pietersz and Marcel van Regenmortel

ERS-2005-010-F\&A

The price of power: valuing the controlling position of owner-managers in french ipo firms Peter Roosenboom and Willem Schramade

ERS-2005-011-F\&A

The Success of Stock Selection Strategies in Emerging Markets: Is it Risk or Behavioral Bias? Jaap van der Hart, Gerben de Zwart and Dick van Dijk ERS-2005-012-F\&A

Sustainable Rangeland Management Using a Multi-Fuzzy Model: How to Deal with Heterogeneous Experts' Knowledge Hossein Azadi, Mansour Shahvali, Jan van den Berg and Nezamodin Faghih ERS-2005-016-F\&A

\footnotetext{
* A complete overview of the ERIM Report Series Research in Management: https://ep.eur.nl/handle/1765/1

ERIM Research Programs:

LIS Business Processes, Logistics and Information Systems

ORG Organizing for Performance

MKT Marketing

F\&A Finance and Accounting

STR Strategy and Entrepreneurship
} 